\title{
Cold Physical Plasma in Cancer Therapy: Mechanisms, Signaling, and Immunity
}

\author{
Fatemeh Faramarzi $\mathbb{D}^{1,2}$ Parisa Zafari ${ }^{10},{ }^{2,3}$ Mina Alimohammadi, ${ }^{3}$ \\ Mohammadreza Moonesi $\mathbb{D}^{2,4}$ Alireza Rafiei $\mathbb{D}^{2,3}$ and Sander Bekeschus $\mathbb{D}^{2,5}$ \\ ${ }^{1}$ Student Research Committee, School of Medicine, Mazandaran University of Medical Science, Iran \\ ${ }^{2}$ Department of Immunology, School of Medicine, Mazandaran University of Medical Science, Sari, Iran \\ ${ }^{3}$ Department of Immunology, School of Medicine, Shahid Beheshti University of Medical Science, Tehran, Iran \\ ${ }^{4}$ Department of Hematology, School of Medicine, Tabriz University of Medical Sciences, Tabriz, Iran \\ ${ }^{5}$ ZIK plasmatis, Leibniz Institute for Plasma Science and Technology (INP), Greifswald, Germany
}

Correspondence should be addressed to Alireza Rafiei; rafiei1710@gmail.com

and Sander Bekeschus; sander.bekeschus@inp-greifswald.de

Received 22 March 2021; Accepted 26 November 2021; Published 24 December 2021

Academic Editor: Karolina Szewczyk-Golec

Copyright (c) 2021 Fatemeh Faramarzi et al. This is an open access article distributed under the Creative Commons Attribution License, which permits unrestricted use, distribution, and reproduction in any medium, provided the original work is properly cited.

\begin{abstract}
Despite recent advances in therapy, cancer still is a devastating and life-threatening disease, motivating novel research lines in oncology. Cold physical plasma, a partially ionized gas, is a new modality in cancer research. Physical plasma produces various physicochemical factors, primarily reactive oxygen and nitrogen species (ROS/RNS), causing cancer cell death when supplied at supraphysiological concentrations. This review outlines the biomedical consequences of plasma treatment in experimental cancer therapy, including cell death modalities. It also summarizes current knowledge on intracellular signaling pathways triggered by plasma treatment to induce cancer cell death. Besides the inactivation of tumor cells, an equally important aspect is the inflammatory context in which cell death occurs to suppress or promote the responses of immune cells. This is mainly governed by the release of damage-associated molecular patterns (DAMPs) to provoke immunogenic cancer cell death (ICD) that, in turn, activates cells of the innate immune system to promote adaptive antitumor immunity. The pivotal role of the immune system in cancer treatment, in general, is highlighted by many clinical trials and success stories on using checkpoint immunotherapy. Hence, the potential of plasma treatment to induce ICD in tumor cells to promote immunity targeting cancer lesions systemically is also discussed.
\end{abstract}

\section{Introduction}

Cold physical plasma is a partially ionized gas operated at or around body temperature [1], and the term "plasma" in this work relates to this gas plasma and not to the protein-rich liquid of blood plasma. Physical plasmas are multicomponent systems as several plasma properties are described, including electrons and ions, electric fields, mild thermal and UV radiation, and reactive oxygen and nitrogen species. The latter will be abbreviated as ROS hereafter as most RNS also contain oxygen. It was recently outlined that ROS are major biomedical effectors of physical plasma treatment in biology and medicine [2].
Physical plasma is produced by different types of plasma devices such as the plasma jet [3-8], dielectric barrier discharge (DBD) [9-13], floating-electrode dielectric barrier discharge (FE-DBD) [14, 15], atmospheric pressure glow discharge torch (APGD-t) [16, 17], plasma brush [18], microhollow cathode discharge air plasma jet [19], microwave plasma torch [20], and nanosecond plasma gun [21]. Plasma jets and DBDs are particularly suitable for biomedical applications as these devices have already entered clinical practice [22]. The first report of using plasma in oncology was published in 2007 by showing the inactivation of melanoma cells in vitro following plasma treatment [14]. After that, more studies provided evidence of the anticancer 
capacity of plasma in several cancer types such as the brain [23-25], skin [26-29], breast [30-34], colorectal [35-37], lung [38-40], cervical [41-43], leukemia [44-48], pancreatic [49-54], liver [55-57], and head and neck [58-60]. Because of altered metabolism and mitochondrial dysfunction, cancer cells are often found to produce more intracellular ROS than nonmalignant cells [61-63]. In some studies, enhanced intracellular ROS in cancer cells makes them more susceptible to cell death induced by extracellular ROS $[64,65]$. Among the extracellular ROS generated via plasma are superoxide anion, hydrogen peroxide, peroxynitrite, nitrite, nitrate, hydroxyl radicals, atomic oxygen, ozone, and singlet delta oxygen [66]. One hypothesis is that aquaporin transporters $[67,68]$ and lower levels of cholesterol in the membrane of cancer cells compared to a nonmalignant cell [69] increase the permeation of ROS through the cancer cell membrane, presumably via lipid peroxidation [70, 71]. As a result, more plasma-produced ROS are being transported to cancer cells, ultimately augmenting cell death. Cell death is a consequence of intracellular signaling regulated by pathways such as signal transducer and activator of transcription 3 (STAT3), MAP-kinase (MAPK) [72], and phosphatidylinositol 3-kinases $(\mathrm{PI} 3 \mathrm{~K})$ via AKT (protein kinase B) [73]. Thus, plasma treatment can selectively target cancer cells because of their unique properties $[67,69]$.

Moreover, several pharmacological and physics approaches have been combined with plasma treatment to additively or synergistically augment toxicity in cancer cells. This includes radiotherapy [74-76], pulsed electric fields [77, 78], hyperthermia [79], photodynamic therapy [80], established anticancer drugs [81-85], and novel anticancer compounds $[86,87]$ including nanoparticles and emulsions [88-103]. This current will not focus on these aspects due to the broad nature of the combination approaches. Instead, plasma treatment has been described to directly or indirectly affect the immune system's cells, which may be harnessed in antitumor therapy [104], and current concepts are described that address this framework. Altogether, this review is aimed at unfolding the mechanisms, pathways, and immune-related activities involved in plasma cancer therapy.

\section{Plasma Devices in Cancer Treatment}

Analyzing plasma devices from different perspectives, including assessing their safety aspects, the capacity of ROS production, and cellular response to oxidative eustress and distress, are critical steps in examining how plasma works in cancer treatment. For a detailed overview of plasma physics, the reader is referred to reviews on this topic [105-107], while this section intends to give a brief overview to the biomedical audience. There are three major types of plasma sources including (1) DBD plasmas, also called "direct" plasma sources, that use the human body as an electrode; (2) plasma needles/plasma jets, also called "indirect" plasma sources, producing a discharge between two electrodes (Figure 1); and (3) hybrid plasma source, the combination of both (1) and (2) plasma sources [108]. The use of these plasma-producing systems depends on the study's purpose, and plasma jets seem more common than DBD plasmas based on several reports [109]. DBD plasmas' advantage is that they do not require a particular gas flow as needed in plasma jets, in which usually a noble gas is excited using high-frequency electrodes. In most cases with DBDs, the DBD electrode needs to be close to the target, and its diameter varies from several millimeters to centimeters [110]. Unlike DBDs, plasma jets use three common gases, including helium $(\mathrm{He})$, argon (Ar), and nitrogen $\left(\mathrm{N}_{2}\right)$, that determine the efficiency and pattern of ROS production [111]. Other critical parameters in operating plasma jets are, for instance, gas flow rate, applied voltage, and the distance from the nozzle to the target. For example, increasing the distance from the target to a jet nozzle decreases the concentration and variety of most reactive species reaching that target, while some, like ozone, are often found to be increased [112]. Also, changes in the feed gas flux are accompanied by changes in the reactive species composition, especially when the flow switches from laminar to turbulent [113, 114]. Another critical factor is exposure time. It is well known from microbiology studies that the growth inhibition zones of bacteria grown on agar increase with a rise in plasma treatment time [115]. Likewise, the plasma treatment time dictates the extent of biological responses, e.g., apoptosis $[110,116]$. Also, exposure time can modulate the secretion of cell-signaling molecules, such as growth factors and cytokines [117]. The plasma devices' operating conditions affect the type and amount of reactive species products, especially in cancer cells $[6,118,119]$. Therefore, regulating these conditions improves plasma efficiency in inhibiting cancer cells (Table 1).

One device that has been successfully employed in cancer treatment in patients $[120,121]$ is the atmospheric pressure argon plasma jet kINPen MED (Figure 2). Generally, medical plasmas are multicomponent systems, while it has been established that the biological activity of plasma treatment is mainly mediated via ROS/RNS and subsequent redox signaling $[2,122]$. The ROS/RNS generation process is briefly described. For plasma jets, a gas is fed into the device. Usually, noble gases such as argon, helium, and neon are used to be ionized easily. These ionized gases are subsequently expelled into the ambient air. Reaction with oxygen and nitrogen takes place, generating reactive oxygen and nitrogen species. Within the plasma plume, hundreds of chemical reactions occur $[123,124]$, leading to the simultaneous generation of a large variety of reactive species [125]. These species have varying concentrations along the axis of the plasma jet and are characterized by individual travel distance and deterioration kinetics in the ambient air [126-128]. This aspect complicates the identification of exact species types and concentrations being delivered to the biological target. As a general measure of species quantification, liquids can be exposed to plasma to identify some species such as nitric oxide, singlet oxygen, hydrogen peroxide, hydroxyl radical, nitrite, nitrate, peroxynitrite, and ozone, based on established redox chemistry assays [66, 129-133]. Notably, there is no tool available to simultaneously investigate all types of species being generated in the plasma gas phase or treated liquids. This also holds true 


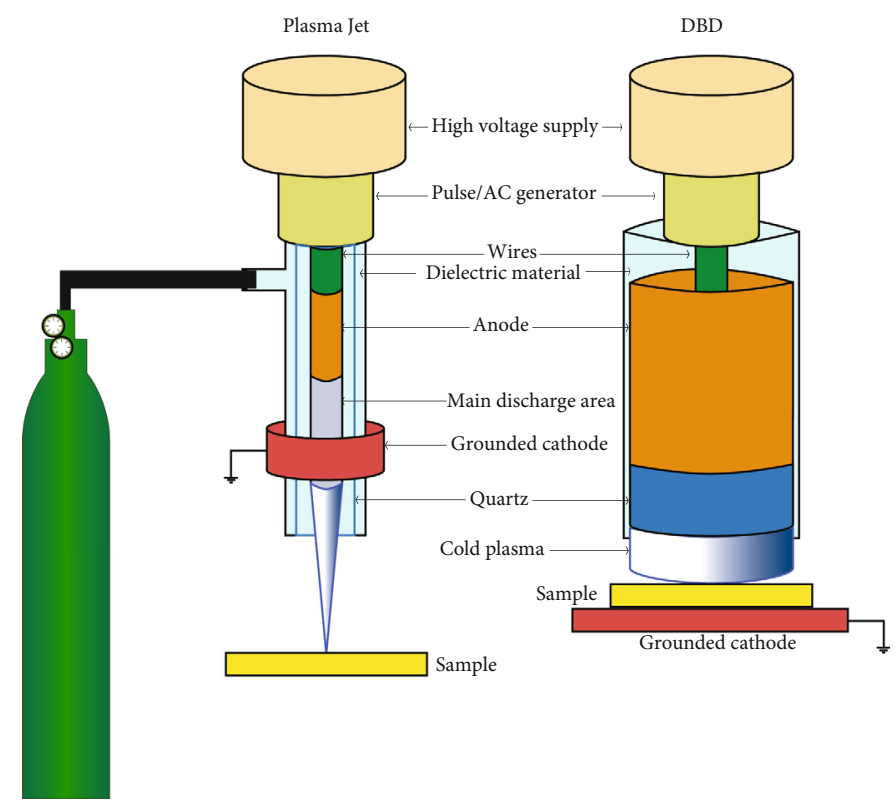

FIGURE 1: Schematic of the principles of plasma jets and dielectric barrier discharges (DBD). In plasma jets, the gas flow is required for the generation of cold physical plasma, while the plasma provided by DBD is created in ambient air. Plasma jets are grounded, while many DBD systems use the treatment target as a grounded cathode to produce cold physical plasma. Many types of gases can be used. Usually, noble gases such as argon, helium, and neon are employed, but air ionization is also feasible with specific parameter setups.

for plasma-treated tissues, as tools for assessing such species directly in such context are currently not available [134].

\section{Cell Death Signaling in Cancer Cells}

Several cell death modalities are known, including necrosis, apoptosis, necroptosis, autophagy, and pyroptosis [135]. These pathways can be a therapeutic target for the control and destruction of cancer cells. Deregulation of cell death signaling is a distinctive feature of cancer cells, and many cancer therapies target the apoptosis signaling machinery, including cell death receptors and mitochondrial signaling pathways $[136,137]$. Direct plasma treatment or plasmatreated liquid (PTL) increases the intracellular ROS affecting different factors in cell death signaling in tumor cells [138]. Accordingly, targeting proteins or kinases involved in cell death signaling can efficiently induce apoptosis and death in the cancer cell. In the following, it will be outlined which pathways are involved in plasma-mediated cell death (Figure 3).

3.1. Apoptosis. It has been found that the ROS produced by plasma can induce cell death in cancer cells by activation of four MAPK pathways, including ERK1/2, c-Jun Nterminal kinase (JNK), p38 MAPK, and ERK5. The JNK and p38 pathways have a crucial role in the induction of apoptosis and the stress of the cells [139]. The activation of these pathways involves proapoptosis $\mathrm{Bcl}-2$ proteins such as BAX and BAK that initiate intrinsic or mitochondrial cell death signaling. Also, p38 MAPK and JNK can upregulate p53 activity that controls cancer growth and triggers cell death in cancer cells [140]. p53 is a tumor suppressor protein involved in stress responses and intrinsic and extrinsic apoptosis pathways [141]. The phosphorylation of p53 triggers the intrinsic apoptosis pathway by activating the $\mathrm{BH} 3$ domain of proapoptotic proteins such as Puma, Noxa, Bad, Bax, Bak, and apoptosis-execution factors such as Apaf1 [136]. Also, p53 can initiate extrinsic apoptotic pathway signaling through cell death receptors such as Fas. Following activation of one of the two (or both) pathways, downstream caspases are activated, and apoptosis occurs. High levels of p53 protein in plasma-treated leukemia cells confirm p53induced apoptosis [46, 136]. Moreover, increased Bax, Bcl-2, and caspase 8 expression in cancer cells after plasma treatment showed the effect of plasma on intrinsic and extrinsic pathways [46].

The ERK pathway is another MAPK pathway that coordinately regulates some essential biological functions of the cells, such as proliferation, differentiation, cycle regulation, apoptosis, and tissue formation. Also, this pathway can be related to tumor proliferation and invasion/metastasis [139]. Accordingly, the regulation of this pathway can be essential in inhibiting tumor cell growth. Plasma therapy has been shown to dramatically increase ERK1/2 phosphorylation and activate caspases in cancer cells, leading to their death [142].

Elevated intracellular ROS activates tumor suppressor proteins and kinases, suppressing the oncogenic PI3K/AKT pathway. Thus, inhibition of the PI3K/AKT pathway initiates cancer cell death [140]. PI3K/AKT signaling mediates a wide range of cellular functions, including transcription, translation, proliferation, growth, and survival. This pathway maintains the balance between cell proliferation and apoptosis in cancer cells and is associated with metastasis 


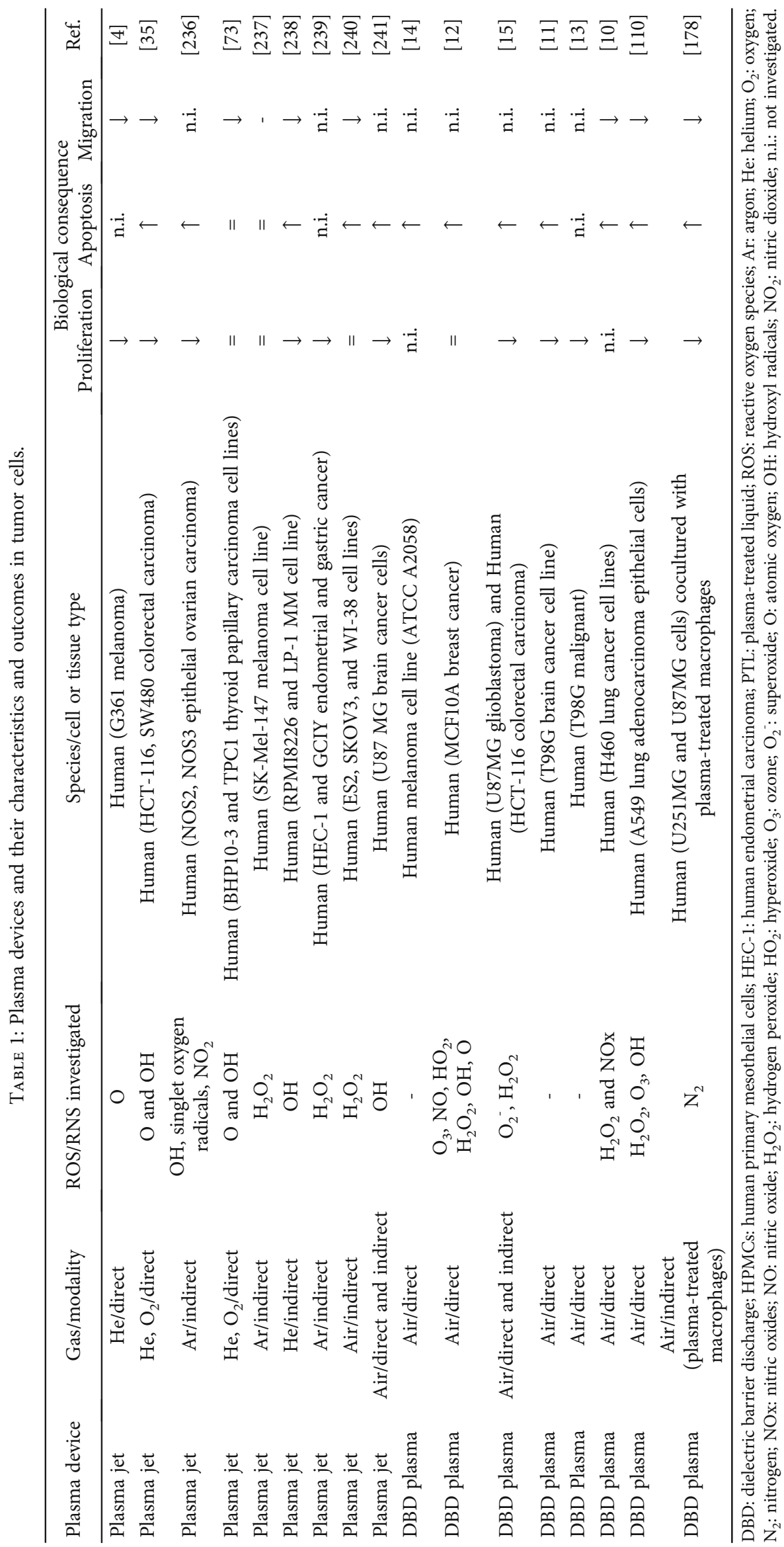




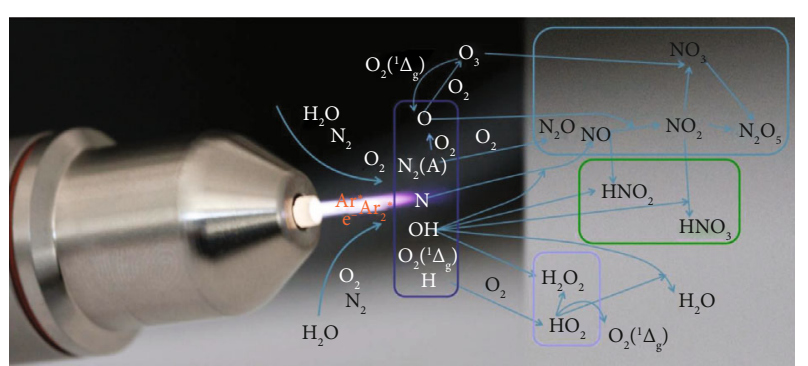

FIgURE 2: The atmospheric pressure argon plasma jet kINPen. The kINPen is a certified medical product in Europe and is regularly employed in dermatology. First initial trials in human cancer patients have been employed. Reproduced from [125].

in some tumors [143]. Also, PI3K/AKT activation has been shown to play a critical role in inhibiting p53. Indeed, plasma therapy downregulates the PI3K/AKT pathway and induces p53-mediated apoptosis and cancer cell death [97]. Nitric oxide (NO), a product of NOX activity in some tumor and innate immune cells, has pro- and anticancer effects. Depending on its intracellular level, low NO levels can promote tumor cell growth, while high NO levels usually cause the tumor cell to die [144]. Physical plasma treatment enhances intracellular NO levels in cancer cells, leading to MAPK p38 activation [144]. This plasma-derived NO was shown to significantly increase the presence of active caspases 3 and 8, confirming the role of plasma in activating caspase cascade and inducing cell death [144].

Moreover, activating protein-1 (AP-1) as a dimeric transcription factor, Fra-1, and c-Jun (highly expressed in invasive cancers) enhance cancer cells' migration and proliferation. Their phosphorylation is often regulated by MAP kinases such as JNK and p38 [145]. Plasma treatment can modulate the expression of AP-1 related transcription factors in cancer cells such as leukemia. It has been reported that JUND, a subfamily of Jun, can trigger phagocyte activation and cytokine secretion such as IL-8 in plasma-treated THP-1 cells [146].

Another pathway involved in cancer cell death is signal transducer and activator of transcription 3 (STAT3) signaling. STAT3 has a role in proliferation, survival, migration, invasion, and angiogenesis [147]. Therefore, targeting this pathway can be efficient in cancer cell inhibition. Plasmatreated osteosarcoma showed an initiation in the apoptotic pathway by reducing phosphorylation in the AMPK or STAT3 pathways, which had an inhibitory effect on cancer cells' growth [148]. Further experiments are needed to explain the effect of plasma on the STAT3 pathway in this area.

3.2. Autophagy. Autophagy is a process that occurs in all cells to eliminate dysfunctional or damaged cell organelles. The autophagic process plays a double-edged sword role in cancer progression [149]. Regulation of autophagy is mediated by tumor suppressor proteins such as LC3 and Beclin1, leading to cancer cells' death. Various environmental stressors such as starvation, hypoxia, and growth factor deprivation can convert LC3 to LC3-II by conjugating a lipid molecule called phosphatidylethanolamine (PE) to incorporate into the autophagosome membrane. Also, Beclin-1 is involved in the very early stage of autophagosome formation $[149,150]$. Plasma-produced ROS increased autophagosome formation through activate ERK1/2 and induce LC3. This is presumably due to ROS stimulating the JNK pathway to phosphorylate Bcl-2 and releasing Beclin-1 associated with LC3 involved in autophagic cell death [151, 152]. Using PTL decreases the phosphorylated mTOR and AKT protein levels, which is critical for cancer cell viability. Besides, PTL increases LC3B expression in endometrial cancer cells. So PTL can inhibit cell viability while inducing autophagic cell death in endometrial cancer cells [153]. Moreover, PTL treatment increases the level of LC3A/B, p-ERK kinase, which is involved in Beclin-1-related autophagy. Indeed PTL induces apoptosis of pancreatic cancer cells through the ROS-dependent autophagy pathway [154]. As a result, JNK phosphorylates the c-Jun protein, which leads to the production of AP-1, which in turn promotes the expression of many genes such as Bax and FasL [151].

3.3. Pyroptosis. Pyroptosis is another type of programmed cell death mediated by the gasdermin family which includes GSDMA, GSDMB, GSDMC, and DFNA5/GSDME [155]. Pyroptosis has some characteristics of apoptosis as well as necrosis. Pyroptotic cells undergo nuclear condensation and chromatin DNA fragmentation, similar to apoptotic cells. In parallel, cell membrane pore formation, cell swelling, cell membrane rupture, and the release of proinflammatory mediators, including IL-1 $\beta$, IL-18, ATP, and HMGB14 during pyroptosis, occur, sharing similar features to necrosis. Therefore, pyroptosis is an inflammatory form of cell death and has a bilateral role in tumor cell progression. Plasma treatment was shown to induce pyroptosis in cancer cells via ROS, promoting the phosphorylation of JNK and increasing cytoplasmic cytochrome C levels [156]. These pathways induced caspase 9 and caspase 3 activation by cleaving GSDME, which induces pyroptosis in cancer cells [157].

3.4. Ferroptosis. Ferroptosis is an iron-dependent and reactive oxygen species- (ROS-) reliant cell death distinct from apoptosis, classic necrosis, autophagy, and other forms of cell death at morphologic, biochemical, and genetic levels [158-160]. Ferroptosis is mainly based on cytological changes, including decreased mitochondrial cristae, a ruptured outer mitochondrial membrane, and a condensed mitochondrial membrane. Excessive membrane lipid peroxidation and the occurrence of oxidative stress cause cell abnormalities in ferroptosis [160]. This form of cell death can be induced by small molecules such as erastin and Ras-selective lethal small molecules (RSL). Also, iron and ROS accumulation, activation of the MAPK pathway, and release of arachidonic acid mediators trigger this type of cell death. However, xCT (SLC7A11) and glutathione peroxidase 4 (GPX4) are critical regulators of ferroptosis [159]. In addition, p53 might act as a rheostat, preventing ferroptosis under basal or low ROS stress while promoting ferroptosis in high oxidative stress conditions [161]. p53 represses the 


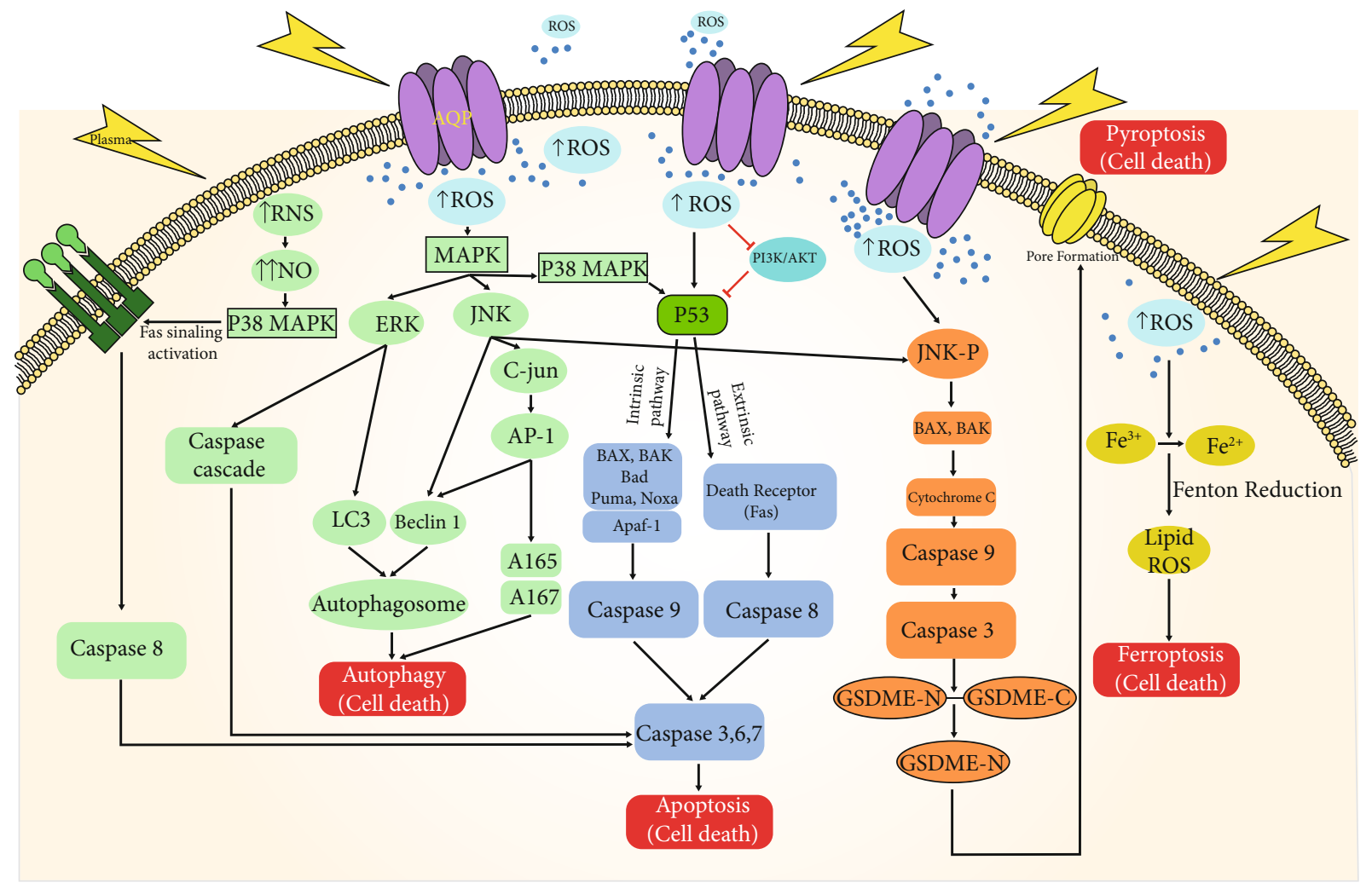

FIGURE 3: Model of three cell death signaling pathways in plasma-treated cancer cells. Plasma exposure increases aquaporin transporters in cancer cell membranes that allow the transport of $\mathrm{H}_{2} \mathrm{O}_{2}$ into the cells. Additionally, plasma treatment oxidizes cellular membranes, leading to cell death signaling. The excessive intracellular ROS contribute to the initiation of the cell death signaling (e.g., apoptosis, autophagy, pyroptosis, and ferroptosis) in cancer cells, partially through the activation of the MAPK pathway.

expression of SLC7A11, a vital component of the cystine/ glutamate antiporter. Hence, p53 can inhibit cystine uptake and sensitizes cells to ferroptosis [162]. Moreover, another study implicated that plasma treatment increases cell death in the samples with lower $\mathrm{xCT}$ expression than samples with higher xCT expression [163].

Excess irons are the basis for ferroptosis. Interestingly, redox-active iron pools (i.e., $\mathrm{Fe}_{2}^{+}$) via Fenton reaction can directly catalyze lipid peroxides, which cause ferroptosis [162]. Accordingly, it was hypothesized that plasma exposure could induce destruction of the shell of ferritin and simultaneous reduction from $\mathrm{Fe}(\mathrm{III})$ to $\mathrm{Fe}(\mathrm{II})$, resulting in Fenton reaction to cause oxidative cell death [164]. Also, plasma exposure may kill oral squamous carcinoma cells through ferroptosis, dependent on ample catalytic Fe(II) [165]. Further studies are required to demonstrate the effect of plasma therapy in cancer cell ferroptosis.

\section{Immune Cell Activation Followed by Plasma Treatment}

Plasma treatment can affect the activation of immune cells and their ability to provide effective antitumor immunity [166]. As currently known, antitumor immune responses consist of innate and adaptive immunity that interacts and acts on cancer cells by various means [104]. The innate immune system can both foster and limit cancer progres- sion through direct interaction with tumor cells and the activation of other cells in the tumor microenvironment (TME) $[167,168]$.

4.1. Immunogenic Cancer Cell Death (ICD). Induction of cell death is an expected valuable outcome in plasma-treated cancer cells. It may also cause tumor cells to externalize or secrete many types of damage-associated molecular patterns (DAMPs), including ATP, high mobility group protein B1 (HMGB1), calreticulin (CRT), and heat shock protein 90 (HSP90), leading to the recruitment of immune cells [169]. CRT and ATP are critical for innate immune cell activation to uptake dead tumor cells to occur in the inflammatory context. This mediates an antitumor immune response by promoting DC maturation and antigen presentation, resulting in T-cell responses against tumor cells [170].

It has been demonstrated that nonthermal plasma treatment induces ICD by the generation of ROS [171] and other charged species [166] and increases the immunogenicity of tumor cells. Plasma upregulates immunogenic cell surface molecules such as MHC-I [172] and surface-exposed calreticulin (ecto-CRT). The latter acts as an Eat Me signal facilitating the recognition, engulfment, and processing of tumor cells by APCs. High levels of extracellular ATP following plasma therapy [173] act as a Find Me signal for the recruitment and activation of APCs in tumor microenvironments (Figure 4). Increased expression of $\mathrm{CD} 45$, a 


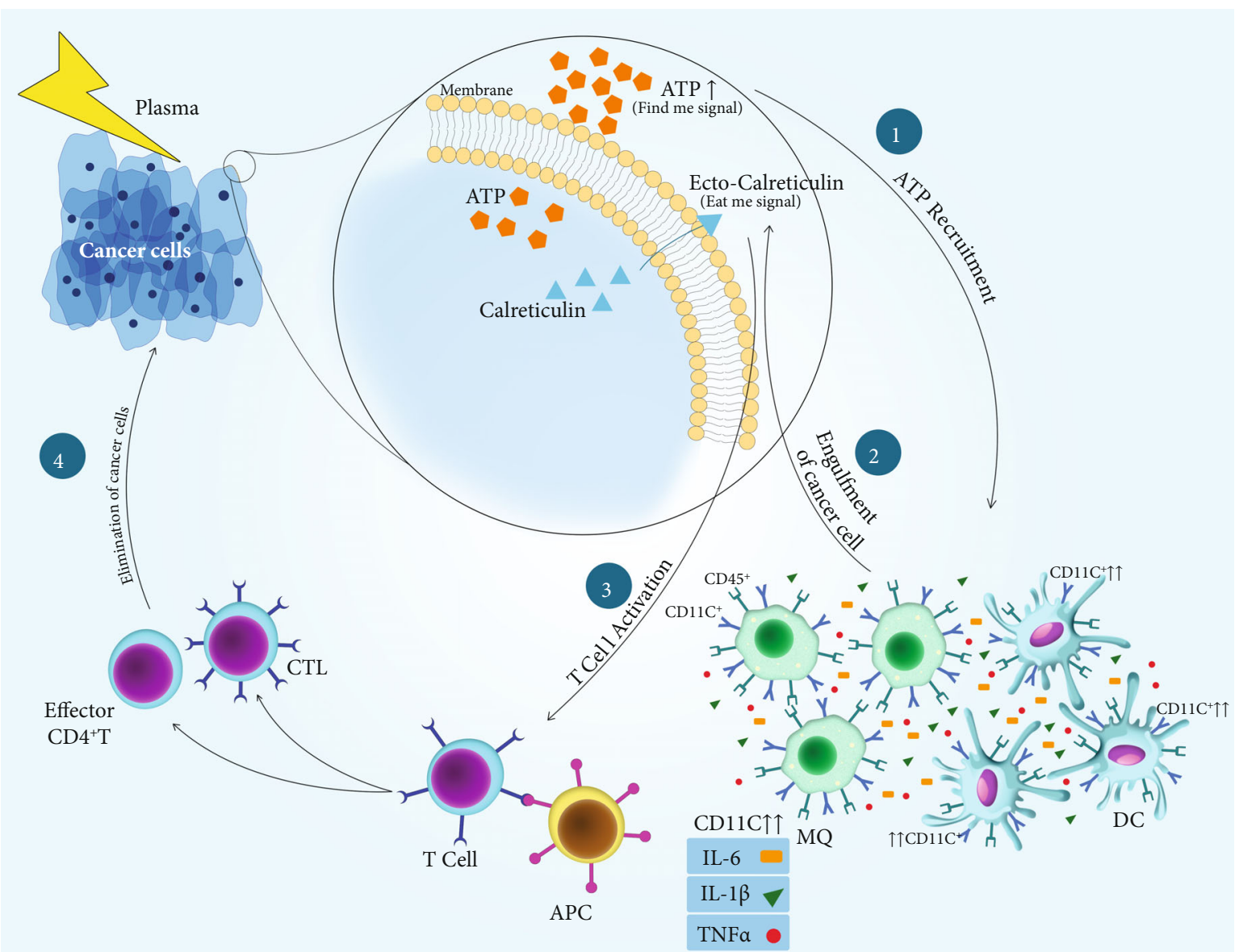

FIGURE 4: Model of plasma-induced immunogenic cell death in cancer cells. Plasma exposure leads to an increase in DAMP signaling (e.g., ATP and calreticulin), which (1) provides inflammatory stimuli for (2) promoting the processing of cancer cells by APCs. Consequently, (3) activated APCs promote the development and activation of (4) effector T-cells, capable of precisely and systemically eradicating cancer cells distant from the site of plasma treatment.

leukocyte marker, and CD11c, an APC marker, in the tumor microenvironment of $\mathrm{BALB} / \mathrm{c}$ mice exposed to the plasma suggested additional leukocytes' recruitment, including APCs, presumably via DAMP signaling $[174,175]$.

4.2. Macrophages. Macrophages are critical immune cells in the TME and play a pivotal role in immune homeostasis. In response to a wide variety of environmental conditions, macrophages can differentiate and polarize into different phenotypes of M1 and M2. Tumor cells release and express molecules that hijack macrophages, supporting tumor growth [176]. In some cancer types, such as in the pancreas and brain, up to $50 \%$ of the cells are macrophages, continually supporting angiogenesis and phagocytose, silently and without inflammation, dead tumor cells. These are called tumor-associated (M2) macrophages. M2 macrophages express CD163 (scavenger receptor) and CD206 (mannose receptor) as anti-inflammatory markers and arginase. In addition, they release IL-10, TGF- $\beta$, and PGE2 and have a higher expression of PD-L1 that can repress antitumor Tcell responses. In turn, however, macrophages can also be licensed to kill tumor cells in the presence of proper proinflammatory stimuli, called proinflammatory (M1) macro- phages [167]. M1 macrophages, as classically activated macrophages, express CD68, CD80, and CD86 costimulatory molecules and can control tumor progression by releasing TNF- $\alpha$, IL- $1 \beta$, IL-12, and iNOS. In the appropriate setting, some cytokines such as INF- $\gamma$ can convert M2 macrophages to the M1 phenotype in the TME $[177,178]$. Another study, however, found an M2 skewing of monocyte-derived macrophages with plasma treatment [179]. While plasma-treated monocytes generated ROS and were susceptible to plasma-induced cell death, as shown before [180], plasma-treated macrophages were not [178].

Using human monocytes, plasma treatment was shown to exacerbate M1 macrophages' cytotoxic activity against tumor cells. This was accompanied by an increased expression of CD86 (M1 marker) and low levels of CD163 and CD206 (M2 markers) on the THP-1-derived macrophages [178]. A similar increase of toxicity was made in A549 lung cancer cells during coculture with THP-1-derived macrophage in vitro [181]. Another study reported that the rate of cell death in a plasma-treated nasopharyngeal carcinoma cell line (CNE-1) cocultured with native (M0) macrophages (macrophages) was higher than the presence of macrophages, possibly due to the increase in extracellular ATP 
[182]. In such coculture systems of cell-line-derived macrophages and tumor cells, elevated levels of TNF- $\alpha$ were also linked to the increased cytotoxicity observed [183]. TNF- $\alpha$ inhibits the tumor progression by activating $\mathrm{CD}^{+} \mathrm{T}$-cells and induces inflammatory cytokines such as IL-1, IL-6, IL8 , and cytotoxic factors like $\mathrm{NO}$ and ROS produced by macrophages and NK cells $[184,185]$. Strikingly, recent evidence suggests that plasma treatment supports monocytes' differentiation process into macrophage-like cells. In contrast to the other studies, this was found in cell lines and using primary monocytes isolated from the human blood [186]. Moreover, plasma treatment of cancer cells and culturing monocytes in these DAMP-containing cancer cell supernatants promoted monocyte activation [123] and their cytotoxicity upon coculture with tumor cells [187].

4.3. Cross-Talk between Dendritic Cells and T-Cells. Activation of T-cells and the generation of long-lived memory cells in the tumor microenvironment (TME) are the critical target of cancer therapies. $\mathrm{CD}^{+} \mathrm{T}$-cells are the key player in the adaptive immune system for the direct killing of cancer cells via the release of cytotoxins, such as perforin and granzyme B. Effector $\mathrm{CD}^{+} \mathrm{T}$-cells in response to an antigenic tumor can secrete cytokines such as IFN- $\gamma$, TNF- $\alpha$, and IL- 2 that limit tumor progression and help the activation of $\mathrm{CD}^{+}$ CTL in a later stage [188]. Activation of adaptive T-cell responses depends on antigen recognition, so antigenpresenting cells (APC) such as DCs play a critical role in stimulating an adaptive immune response, especially cytotoxic $\mathrm{CD}^{+}$T-cells and $\mathrm{CD}^{+}$T-cells. DCs are innate immune cells known as professional APC and play a crucial role in linking innate and adaptive immune responses. DCs phagocytose, process, and present the tumor antigens to naïve antigen-specific $\mathrm{CD} 4^{+}$or $\mathrm{CD} 8^{+} \mathrm{T}$-cells via major histocompatibility complexes (MHC) II and I, respectively. There are two major subsets of DC: classical/conventional DC (cDC) and plasmacytoid DC (pDC). pDC produces type I interferons, which are essential in the stimulation of antitumor immune response. They can also generate regulatory T-cells $\left(\mathrm{T}_{\text {reg }}\right)$ in the tumor microenvironment, which favors tumor progression. Depending on their subtype, cDCs present tumor antigens to prime both $\mathrm{CD}^{+}$and CD4 ${ }^{+}$T-cells [189].

It was previously speculated that plasma-derived ROS treatment of tumor cells initiates the cancer-immunity cycle by promoting ICD, DC maturation, and priming of antitumor T-cells in the draining lymph node [190, 191]. A recent in vivo report supports this claim by providing evidence for ICD and subsequent DC activation together with checkpoint therapy-augmented plasma and abscopal effects in a melanoma model [192]. Using the same cell type but a different type of plasma source, ICD and the subsequent protection from tumor growth in a preventive vaccination model were shown, and mechanistically, the effects were deduced to the action of short-lived ROS [193]. In vitro, plasmatreated PBS activity on tumor cells may be involved in DC maturation. Also, higher levels of TNF- $\alpha$ and IFN- $\gamma$ and decreased levels of immunosuppressive cytokines such as TGF- $\beta$ produced by DC cocultured with tumor cells exposed to plasma-treated PBS an immune-enhancing effect of this approach [194]. Moreover, other in vitro studies suggested a distinct cytokine profile and modest but evident DC activation in the presence of directly plasma-killed tumor cells [74, 173]. It was recently reported for a translational researchrelevant plasma jet accredited as a medical device in Europe that plasma treatment not only induced ICD in melanoma cells that were successfully used as a preventive vaccine in mice but also was accompanied by an increased influx of $\mathrm{CD}^{+}$and $\mathrm{CD}^{+}$T-cells in the TME along with their increased activation and memory phenotype [195]. Moreover, increased efficacy of plasma treatment was demonstrated when combined with a toll-like-receptor (TLR) agonist activating DCs and superior efficacy of one plasmaderived ROS cocktail rich in atomic oxygen over other ROS cocktails. These findings corroborated previous reports on increased T-cell infiltrates in plasma-treated syngeneic melanomas in vivo [196, 197]. In addition, it was recently shown in vitro and in vivo that the immunogenicity plasma-treated protein can confer immunoprotection in mice against melanoma growth [198], giving rise to entire novel concepts in plasma oncotherapy [199].

\section{Clinical Trials and Case Series on Plasma Therapy in Medicine including Cancer}

In vivo and in vitro studies in plasma medicine have shown promising results, encouraging clinicians to evaluate plasma therapy in clinical settings across several types of diseases (Table 2). Since there is only a few reports on plasma anticancer studies, other clinical applications are described as well in the following. For each plasma device, such studies must demonstrate safe plasma treatment in the first clinical step.

5.1. Case Series. Several case series and reports have reported on the use of different plasma devices in humans to treat disease. In Greifswald, Germany, clinicians investigated the clinical application of cold physical plasma treatment in 21 patients with advanced head and neck cancer in a palliative setting. This study was aimed at evaluating tumor surface changes and the ratio of apoptotic cancer cells, respectively, in group I and group II. Among the 12 patients in group I, there was no enhanced or stimulated tumor growth under two weeks after cold physical plasma treatment. The result of 9 patients in group II showed more frequent apoptotic cells in tissue areas treated by plasma than in untreated areas $[120,121,200]$.

Moreover, German clinicians used a plasma device to treat six patients suffering from wound healing disturbances after maxillofacial surgical procedures. The size and localization of the defect were different among all cases, so plasma therapy was initiated at various postsurgery times, ranging from 2 to 42 weeks. The primary outcome showed complete healing, defined as wound closure and the absence of any signs of infection. Besides, the secondary outcomes showed complete remission after 48 weeks of plasma treatment. In that study, several therapeutic properties of plasma, including antibacterial effect, stimulation of tissue 


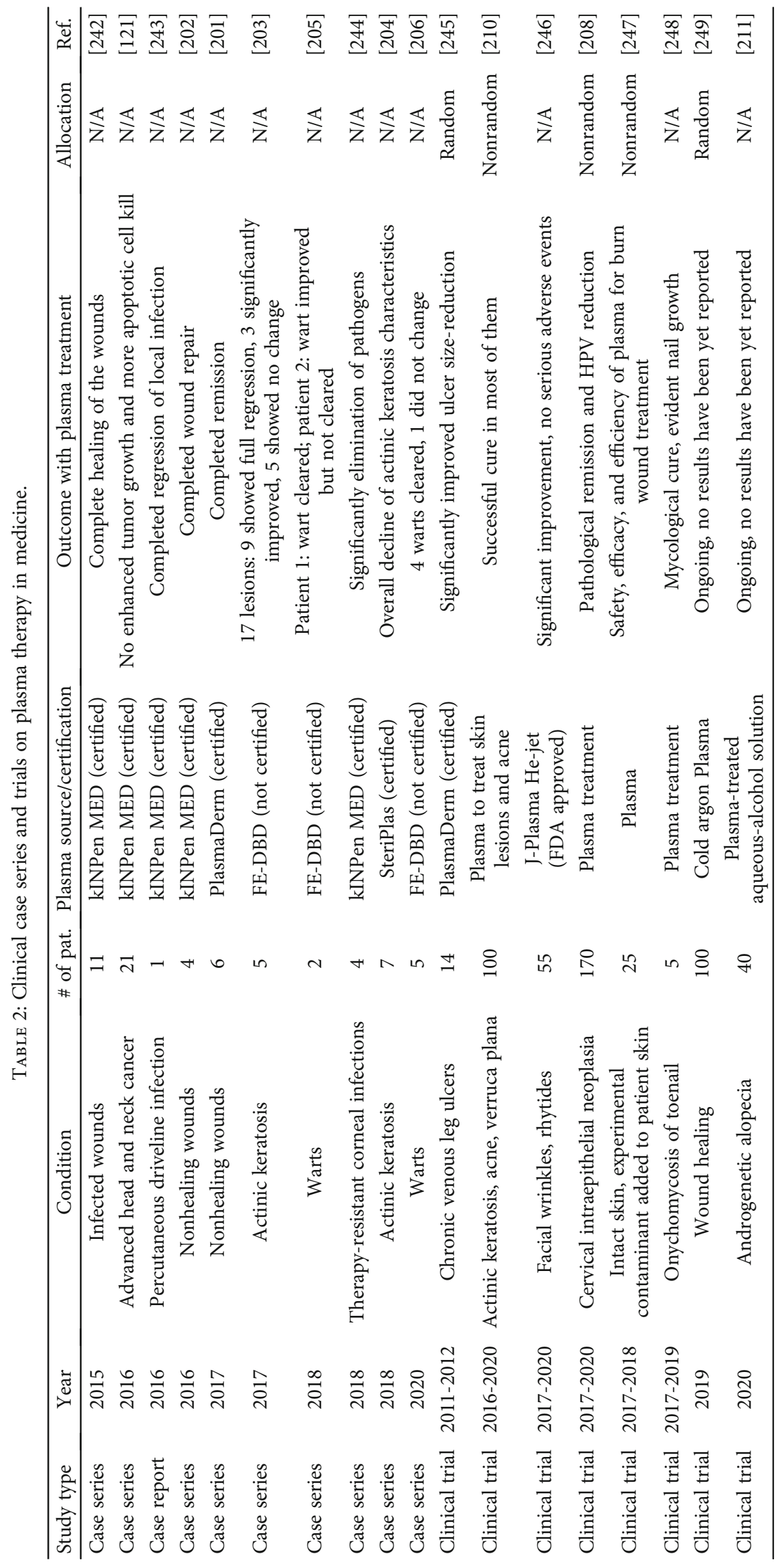


repair, regeneration, neovascularization, and skin microcirculation, were considered. Based on the results, plasma is a promising approach to treat chronic healing disorders of wounds resulting from CMF surgery [201]. Another study by the same authors evaluated the effect of plasma therapy on wound healing disorder following the radial forearm free flap (RFFF) procedure. The endpoint of this therapy showed the successful remission of wounds. It was concluded that plasma treatment possibly is a new therapeutic modality to avoid repeated surgery [202].

Actinic keratosis $(\mathrm{AK})$ was another skin disease that has been investigated to be treated using plasma. In one study, 17 lesions were plasma-treated and followed up for one month without interval evaluation. Three lesions improved significantly, and the condition of five lesions did not worsen. Interestingly, none of the patients experienced side effects, such as pain and inflammation during treatment [203]. All patients showed a decline in AK characteristics such as erythema, scaling, crusts, and thickness, and in some cases, the total lesion number was decreased [204].

The efficacy of plasma therapy has also been investigated in the treatment of wart lesions. The results of one study revealed that all lesions of the first patient faded after 2 to 3 plasma exposure cycles. In a second patient, however, the lesions were improved but did not disappear completely [205]. The same authors demonstrated that plasma exposure could also be an effective modality for wart treatment in pediatric patients [206]. The plasma device used in this study is currently not approved by the FDA. Nevertheless, plasma treatment was suggested to induce apoptosis in malignant cells ex vivo [207], so it seems likely that this also holds for premalignant cells. However, clinical data are insufficient to confirm the plasma mechanism in improving the wart [206].

Overall, plasma therapy is a novel promising therapeutic tool in managing tumor cells and the recovery of infection, postoperative wound healing, actinic keratosis, and wart disorders.

5.2. Clinical Trials. The first registered clinical trial on plasma cancer treatment was initiated in Tübingen, Germany, in 2017 to manage cervical intraepithelial neoplasia. Approximately 170 patients were planned to participate in the study. Final results, however, were not reported yet apart from the observation that pathological remission and HPV reduction were secondary outcomes [208]. In 2019, a U.S. company used plasma to treat 20 patients with breast and lung cancer after standard treatments, including chemotherapy, radiation, and surgery. Preliminary results suggested a preferential targeting of tumor cells, but further confirmation is awaited. This technology was the first to be approved in an FDA phase I clinical trial in August 2019 [209]. Moreover, the Skin Center Dermatology Group investigated the effect of plasma to treat 100 subjects with skin disorders. This study enrolled 100 participants suffering from actinic keratosis, acne, or verruca plana. The results of the plasma treatment were successful in most cases and showed no side effects. However, this study has not yet been completed and final results are awaited
[210]. A recent clinical study examined the effect of plasma in the treatment of hair loss. This study started on June 8, 2020, and is currently recruiting. However, no results have yet been reported [211].

\section{Side Effects of Plasma Treatment}

Any medical treatment has to meet both efficacy and safety requirements. While many studies had investigated the efficacy of plasma treatment in many types of diseases, studies on their safe applications are less frequent. The main agents of biomedical plasma effects, ROS, are also produced during physiological processes in the body. Hence, ROS are not toxic or dangerous per se, but their exacerbated concentration or application frequency might be. To understand this from a practical point of view, it needs to be mentioned that $\mathrm{H}_{2} \mathrm{O}_{2}$ at molar concentrations (e.g., $3 \%$ equals $1 \mathrm{M}$ ) is used for wound disinfection and dentistry. For comparison, to reach the concentration of $1 \mathrm{M} \mathrm{H}_{2} \mathrm{O}_{2}$ in $1 \mathrm{ml}$ of a saline solution, this would translate to a plasma treatment time of $30.000 \mathrm{~min}$ (or $500 \mathrm{~h}$ ) for an accredited argon plasma jet [212]. For in vitro, in vivo (mice), and patient treatment with this jet, typical treatment times are between $5 \mathrm{~s}$ and $3 \mathrm{~min}$ $[213,214]$. This calculation emphasizes that the ROS doses generated with plasma treatment range from inducing ROS-related (cell death) signaling rather than overloading the cells with necrotic doses of ROS and would account for most medically suited plasma devices currently in use.

Nevertheless, several safety studies have been performed, especially for the well-characterized kINPen MED [215]. This plasma jet does not generate mutagenic events, as shown using the OECD-accredited HRPT test and the cytokinesis-block micronucleus assay [216, 217]. Notably, the phosphorylation of the histone $2 \mathrm{~A}-\mathrm{X}$ seems a secondary event due to plasma-induced cell death rather than direct DNA damage [218]. In vivo, no formation of micronuclei was observed [219]. In a wound-healing model in mice, the animals were plasma-treated for seven days using the kINPen, and one year later, the animals were investigated using MR-imaging, CT-scanning, histopathology, and tumor marker analysis in the blood and tissues [220]. No tumor formation or any other detrimental long-term effect was observed. Concerning mucosal tissue in mice, plasma exposure caused mild inflammation, and the epithelial layers healed without showing signs of hyperplasia or dysplasia [221]. Side effects in patients were recently summarized [215] and currently extended to the first 5-year follow-up in plasma-treated wounds [222]. In patients suffering from advanced squamous cell carcinoma of the head and neck, some side effects such as bad taste, fatigue, and bleeding were seen in some cases after plasma treatment. However, all of the side effects were mild to moderate and not lifethreatening [223].

For plasma devices other than the kINPen MED, safety has been implied as well, albeit less systemically. For instance, this accounts for the PlasmaDerm and SteriPlas devices [224-227], and the efficacy and safety of plasma wound treatment have been reviewed in a meta-analysis recently [228]. Moreover, the number of clinical trials 
indicates a preevaluation (e.g., CE mark in Europe) of the safety across many other plasma sources as a prerequisite to clinical use. In Europe, several medical plasma device types have been employed over the last seven years in over 100 clinical centers and thousands of applications already without any note of severe side effects. It is important to note that there are many plasma devices for cosmetic application on several international markets, but their safety has been addressed to a minimal extent only in most cases. Besides, several plasma devices or device modifications that are not in clinical use yet but are aimed for such application have undergone in vitro or in vivo risk assessments already [229-234]. A DIN spec has been published in Germany that suggests several assays that should be performed for a standard characterization of medical plasma devices [235]. A DIN spec is a legal norm in Germany that describes detailed methods and assays to characterize a product, process, or device based on industry consensus. Current efforts are aimed at generating a respective ISO-norm for the safety of plasma devices that would harmonize risk assessments to ensure the safety and efficacy of plasma treatment of human diseases.

\section{Conclusion}

This review summarizes the recent advances in understanding plasma therapy in medicine, emphasizing cancer treatment. Studies of plasma therapy in the clinical setting have only begun, but promising results were reported so far. Cold physical plasma alters many features of tumor cells, ultimately leading to their demise. Plasma also promotes inflammatory signaling pathways that can augment antitumor responses by innate and adaptive immune cells. Further studies are required to demonstrate the effect of plasma on memory cells' generation against tumor cells. Because plasma releases tumor-associated antigens and facilitates antigen processing, using a combination of plasma and immunotherapy regimens, such as immune checkpoint inhibitors, possibly enhances antitumor immune responses.

\section{Conflicts of Interest}

The authors declare that no conflict of interest exists with the publication of this article.

\section{Authors' Contributions}

All authors prepared the draft and finalized the manuscript. Alireza Rafiei and Sander Bekeschus contributed equally to this work as last authors.

\section{Acknowledgments}

SB is supported by the German Federal Ministry of Education and Research (BMBF), grant number 03Z22DN11.

\section{References}

[1] K. D. Weltmann, E. Kindel, T. von Woedtke, M. Hähnel, M. Stieber, and R. Brandenburg, "Atmospheric-pressure plasma sources: prospective tools for plasma medicine," Pure and Applied Chemistry, vol. 82, no. 6, pp. 1223-1237, 2010.

[2] A. Privat-Maldonado, A. Schmidt, A. Lin et al., "Ros from physical plasmas: redox chemistry for biomedical therapy," Oxidative Medicine and Cellular Longevity, vol. 2019, Article ID 9062098, 29 pages, 2019.

[3] A. Shashurin, M. Keidar, S. Bronnikov, R. A. Jurjus, and M. A. Stepp, "Living tissue under treatment of cold plasma atmospheric jet," Applied Physics Letters, vol. 93, no. 18, p. 181501, 2008.

[4] H. J. Lee, C. H. Shon, Y. S. Kim, S. Kim, G. C. Kim, and M. G. Kong, "Degradation of adhesion molecules of g361 melanoma cells by a non-thermal atmospheric pressure microplasma," New Journal of Physics, vol. 11, no. 11, article 115026, 2009.

[5] J. Y. Kim, Y. Wei, J. Li et al., "Single-cell-level microplasma cancer therapy," Small, vol. 7, no. 16, pp. 2291-2295, 2011.

[6] H. J. Ahn, K. I. Kim, G. Kim, E. Moon, S. S. Yang, and J. S. Lee, "Atmospheric-pressure plasma jet induces apoptosis involving mitochondria via generation of free radicals," PLoS One, vol. 6, no. 11, article e28154, 2011.

[7] S. Mashayekh, H. Rajaee, M. Akhlaghi, B. Shokri, and Z. M. Hassan, "Atmospheric-pressure plasma jet characterization and applications on melanoma cancer treatment (b/16f10)," Physics of Plasmas, vol. 22, no. 9, article 093508, 2015.

[8] K. Kim, J. D. Choi, Y. C. Hong et al., “Atmospheric-pressure plasma-jet from micronozzle array and its biological effects on living cells for cancer therapy," Applied Physics Letters, vol. 98, no. 7, article 073701, 2011.

[9] M. Kuchenbecker, N. Bibinov, A. Kaemlimg, D. Wandke, P. Awakowicz, and W. Viöl, "Characterization of dbd plasma source for biomedical applications," Journal of Physics D: Applied Physics, vol. 42, no. 4, article 045212, 2009.

[10] K. Panngom, K. Y. Baik, M. K. Nam, J. H. Han, H. Rhim, and E. H. Choi, "Preferential killing of human lung cancer cell lines with mitochondrial dysfunction by nonthermal dielectric barrier discharge plasma," Cell Death \& Disease, vol. 4, no. 5, article e642, 2013.

[11] N. K. Kaushik, H. Uhm, and E. H. Choi, "Micronucleus formation induced by dielectric barrier discharge plasma exposure in brain cancer cells," Applied Physics Letters, vol. 100, 2012.

[12] S. Kalghatgi, C. M. Kelly, E. Cerchar et al., "Effects of nonthermal plasma on mammalian cells," PLoS One, vol. 6, article e16270, 2011.

[13] N. K. Kaushik, P. Attri, N. Kaushik, and E. H. Choi, "A preliminary study of the effect of dbd plasma and osmolytes on t98g brain cancer and hek non-malignant cells," Molecules, vol. 18, pp. 4917-4928, 2013.

[14] G. Fridman, A. Shereshevsky, M. M. Jost et al., "Floating electrode dielectric barrier discharge plasma in air promoting apoptotic behavior in melanoma skin cancer cell lines," Plasma Chemistry and Plasma Processing, vol. 27, pp. 163176, 2007.

[15] M. Vandamme, E. Robert, S. Lerondel et al., "Ros implication in a new antitumor strategy based on non-thermal plasma," International Journal of Cancer, vol. 130, pp. 2185-2194, 2012.

[16] M. Leduc, S. Coulombe, and R. L. Leask, "Atmospheric pressure plasma jet deposition of patterned polymer films for cell culture applications," IEEE Transactions on Plasma Science, vol. 37, pp. 927-933, 2009. 
[17] S. Coulombe, V. Léveillé, S. Yonson, and R. L. Leask, "Miniature atmospheric pressure glow discharge torch (APGD-t) for local biomedical applications," Pure and Applied Chemistry, vol. 78, pp. 1147-1156, 2006.

[18] Y. Duan, C. Huang, and Q. S. Yu, "Cold plasma brush generated at atmospheric pressure," The Review of Scientific Instruments, vol. 78, article 015104, 2007.

[19] J. F. Kolb, A. A. H. Mohamed, R. O. Price et al., "Cold atmospheric pressure air plasma jet for medical applications," Applied Physics Letters, vol. 92, article 241501, 2008.

[20] N. Y. Babaeva, G. V. Naidis, D. V. Tereshonok et al., "Production of active species in an argon microwave plasma torch," Journal of Physics D: Applied Physics, vol. 51, 2018.

[21] L. Brulle, M. Vandamme, D. Ries et al., "Effects of a non thermal plasma treatment alone or in combination with gemcitabine in a MIA PaCa2-luc orthotopic pancreatic carcinoma model," PLoS One, vol. 7, 2012.

[22] H.-R. Metelmann, T. von Woedtke, and K.-D. Weltmann, Comprehensive Clinical Plasma Medicine, 2018.

[23] N. D. Almeida, A. L. Klein, E. A. Hogan et al., "Cold atmospheric plasma as an adjunct to immunotherapy for glioblastoma multiforme," World Neurosurgery, vol. 130, pp. 369376, 2019.

[24] Z. Chen, H. Simonyan, X. Cheng et al., "A novel micro cold atmospheric plasma device for glioblastoma both in vitro and in vivo," Cancers (Basel), vol. 9, 2017.

[25] M. Adhikari, B. Adhikari, A. Adhikari et al., "Cold atmospheric plasma as a novel therapeutic tool for the treatment of brain cancer," Current Pharmaceutical Design, vol. 26, pp. 2195-2206, 2020.

[26] G. Pasqual-Melo, R. K. Gandhirajan, I. Stoffels, and S. Bekeschus, "Targeting malignant melanoma with physical plasmas," Clinical Plasma Medicine, vol. 10, pp. 1-8, 2018.

[27] C. Schneider, L. Gebhardt, S. Arndt et al., "Acidification is an essential process of cold atmospheric plasma and promotes the anti-cancer effect on malignant melanoma cells," Cancers (Basel), vol. 11, 2019.

[28] D. K. Yadav, M. Adhikari, S. Kumar et al., "Cold atmospheric plasma generated reactive species aided inhibitory effects on human melanoma cells: an in vitro and in silico study," Scientific Reports, vol. 10, p. 3396, 2020.

[29] A. Rafiei, F. Sohbatzadeh, S. Hadavi, S. Bekeschus, M. Alimohammadi, and R. Valadan, "Inhibition of murine melanoma tumor growth in vitro and in vivo using an argon-based plasma jet," Clinical Plasma Medicine, vol. 1920, 2020.

[30] L. Xiang, X. Xu, S. Zhang, D. Cai, and X. Dai, "Cold atmospheric plasma conveys selectivity on triple negative breast cancer cells both in vitro and in vivo," Free Radical Biology \& Medicine, vol. 124, pp. 205-213, 2018.

[31] S. Park, H. Kim, H. W. Ji et al., "Cold atmospheric plasma restores paclitaxel sensitivity to paclitaxel-resistant breast cancer cells by reversing expression of resistance-related genes," Cancers (Basel), vol. 11, p. 2011, 2019.

[32] S. Bekeschus, M. Lippert, K. Diepold, G. Chiosis, T. Seufferlein, and N. Azoitei, "Physical plasma-triggered ros induces tumor cell death upon cleavage of hsp90 chaperone," Scientific Reports, vol. 9, p. 4112, 2019.

[33] M. Wang, B. Holmes, X. Cheng, W. Zhu, M. Keidar, and L. G. Zhang, "Cold atmospheric plasma for selectively ablating metastatic breast cancer cells," PLoS One, vol. 8, article e73741, 2013.

[34] Z. Yazdani, P. Mehrabanjoubani, P. Biparva, and A. Rafiei, "Cytotoxicity effect of cold atmospheric plasma on melanoma (B16-F10), breast (MCF-7) and lung (A549) cancer cell lines compared with normal cells," Journal of Mazandaran University of Medical Sciences, vol. 30, pp. 38-48, 2020.

[35] C. H. Kim, J. H. Bahn, S. H. Lee et al., "Induction of cell growth arrest by atmospheric non-thermal plasma in colorectal cancer cells," Journal of Biotechnology, vol. 150, pp. 530-538, 2010.

[36] C. H. Kim, S. Kwon, J. H. Bahn et al., "Effects of atmospheric nonthermal plasma on invasion of colorectal cancer cells," Applied Physics Letters, vol. 96, article 243701, 2010.

[37] S. Bekeschus, E. Freund, K. Wende, R. K. Gandhirajan, and A. Schmidt, "Hmox1 upregulation is a mutual marker in human tumor cells exposed to physical plasma-derived oxidants," Antioxidants (Basel), vol. 7, 2018.

[38] H. M. Joh, J. Y. Choi, S. J. Kim, T. H. Chung, and T. H. Kang, "Effect of additive oxygen gas on cellular response of lung cancer cells induced by atmospheric pressure helium plasma jet," Scientific Reports, vol. 4, p. 6638, 2014.

[39] Y. J. Cheng, C. K. Lin, C. Y. Chen et al., "Plasma-activated medium as adjuvant therapy for lung cancer with malignant pleural effusion," Scientific Reports, vol. 10, p. 18154, 2020.

[40] E. A. Golubitskaya, O. S. Troitskaya, E. V. Yelak et al., "Cold physical plasma decreases the viability of lung adenocarcinoma cells," Acta Naturae, vol. 11, pp. 16-19, 2019.

[41] L. Feil, A. Koch, R. Utz et al., "Cancer-selective treatment of cancerous and non-cancerous human cervical cell models by a non-thermally operated electrosurgical argon plasma device," Cancers (Basel), vol. 12, 2020.

[42] M. A. Jezeh, T. Tayebi, M. R. Khani, H. Niknejad, and B. Shokri, "Direct cold atmospheric plasma and plasmaactivated medium effects on breast and cervix cancer cells," Plasma Processes and Polymers, vol. 17, no. 11, 2020.

[43] B. S. Kwon, E. H. Choi, B. Chang, J. H. Choi, K. S. Kim, and H. K. Park, "Selective cytotoxic effect of non-thermal micro-dbd plasma," Physical Biology, vol. 13, article 056001, 2016.

[44] E. Turrini, R. Laurita, E. Simoncelli et al., "Plasma-activated medium as an innovative anticancer strategy: insight into its cellular and molecular impact on in vitro leukemia cells," Plasma Processes and Polymers, vol. 17, no. 10, p. 2000007, 2020.

[45] S. Bekeschus, K. Wende, M. M. Hefny et al., "Oxygen atoms are critical in rendering thp-1 leukaemia cells susceptible to cold physical plasma-induced apoptosis," Scientific Reports, vol. 7, p. 2791, 2017.

[46] E. Turrini, R. Laurita, A. Stancampiano et al., "Cold atmospheric plasma induces apoptosis and oxidative stress pathway regulation in t-lymphoblastoid leukemia cells," Oxidative Medicine and Cellular Longevity, vol. 2017, Article ID 4271065, 13 pages, 2017.

[47] S. Bekeschus, A. Schmidt, L. Bethge et al., "Redox stimulation of human THP-1 monocytes in response to cold physical plasma," Oxidative Medicine and Cellular Longevity, vol. 2016, Article ID 5910695, 11 pages, 2016.

[48] M. Thiyagarajan, H. Anderson, and X. F. Gonzales, "Induction of apoptosis in human myeloid leukemia cells by remote 
exposure of resistive barrier cold plasma," Biotechnology and Bioengineering, vol. 111, pp. 565-574, 2014.

[49] A. Azzariti, R. M. Iacobazzi, R. Di Fonte et al., "Plasmaactivated medium triggers cell death and the presentation of immune activating danger signals in melanoma and pancreatic cancer cells," Scientific Reports, vol. 9, p. 4099, 2019.

[50] K. R. Liedtke, S. Diedrich, O. Pati et al., "Cold physical plasma selectively elicits apoptosis in murine pancreatic cancer cells in vitro and in ovo," Anticancer Research, vol. 38, pp. 5655$5663,2018$.

[51] Z. Chen, L. Lin, E. Gjika, X. Cheng, J. Canady, and M. Keidar, "Selective treatment of pancreatic cancer cells by plasma-activated saline solutions," IEEE Transactions on Radiation and Plasma Medical Sciences, vol. 2, pp. 116-120, 2018.

[52] S. Bekeschus, E. Freund, C. Spadola et al., "Risk assessment of kINPen plasma treatment of four human pancreatic cancer cell lines with respect to metastasis," Cancers (Basel), vol. 11, p. 1237, 2019.

[53] Y. Sato, S. Yamada, S. Takeda et al., "Effect of plasmaactivated lactated Ringer's solution on pancreatic cancer cells in vitro and in vivo," Annals of Surgical Oncology, vol. 25, pp. 299-307, 2018.

[54] R. Verloy, A. Privat-Maldonado, E. Smits, and A. Bogaerts, "Cold atmospheric plasma treatment for pancreatic cancerthe importance of pancreatic stellate cells," Cancers (Basel), vol. 12, 2020.

[55] B. Smolkova, M. Lunova, A. Lynnyk et al., "Non-thermal plasma, as a new physicochemical source, to induce redox imbalance and subsequent cell death in liver cancer cell lines," Cellular Physiology and Biochemistry, vol. 52, pp. 119-140, 2019.

[56] X. H. Zhang, M. J. Li, R. L. Zhou, K. C. Feng, and S. Z. Yang, "Ablation of liver cancer cells in vitro by a plasma needle," Applied Physics Letters, vol. 93, 2008.

[57] J. Duan, X. Lu, and G. He, "The selective effect of plasma activated medium in an in vitro co-culture of liver cancer and normal cells," Journal of Applied Physics, vol. 121, article 013302, 2017.

[58] J. Berner, C. Seebauer, S. K. Sagwal et al., "Medical gas plasma treatment in head and neck cancer-challenges and opportunities," Applied Sciences, vol. 10, 2020.

[59] C. Welz, S. Emmert, M. Canis et al., "Cold atmospheric plasma: a promising complementary therapy for squamous head and neck cancer," PLoS One, vol. 10, article e0141827, 2015.

[60] R. Guerrero-Preston, T. Ogawa, M. Uemura et al., "Cold atmospheric plasma treatment selectively targets head and neck squamous cell carcinoma cells," International Journal of Molecular Medicine, vol. 34, pp. 941-946, 2014.

[61] S. Galadari, A. Rahman, S. Pallichankandy, and F. Thayyullathil, "Reactive oxygen species and cancer paradox: to promote or to suppress?," Free Radical Biology \& Medicine, vol. 104, pp. 144-164, 2017.

[62] J. N. Moloney and T. G. Cotter, "Ros signalling in the biology of cancer," Seminars in Cell \& Developmental Biology, vol. 80, pp. 50-64, 2018.

[63] A. Glasauer and N. S. Chandel, "Targeting antioxidants for cancer therapy," Biochemical Pharmacology, vol. 92, pp. 90$101,2014$.
[64] H. Kong and N. S. Chandel, "Regulation of redox balance in cancer and T cells," The Journal of Biological Chemistry, vol. 293, pp. 7499-7507, 2018.

[65] D. Trachootham, J. Alexandre, and P. Huang, "Targeting cancer cells by ros-mediated mechanisms: a radical therapeutic approach?," Nature Reviews Drug Discovery, vol. 8, pp. 579-591, 2009.

[66] K. Wende, T. von Woedtke, K. D. Weltmann, and S. Bekeschus, "Chemistry and biochemistry of cold physical plasma derived reactive species in liquids," Biological Chemistry, vol. 400, pp. 19-38, 2018.

[67] D. Yan, A. Talbot, N. Nourmohammadi, J. H. Sherman, $\mathrm{X}$. Cheng, and M. Keidar, "Toward understanding the selective anticancer capacity of cold atmospheric plasma-a model based on aquaporins (review)," Biointerphases, vol. 10, article 040801, 2015.

[68] M. Yusupov, D. Y. Yan, R. M. Cordeiro, and A. Bogaerts, "Atomic scale simulation of $\mathrm{H}_{2} \mathrm{O}_{2}$ permeation through aquaporin: toward the understanding of plasma cancer treatment," Journal of Physics D: Applied Physics, vol. 51, 2018.

[69] J. Van der Paal, C. Verheyen, E. C. Neyts, and A. Bogaerts, "Hampering effect of cholesterol on the permeation of reactive oxygen species through phospholipids bilayer: possible explanation for plasma cancer selectivity," Scientific Reports, vol. 7, p. 39526, 2017.

[70] J. Van der Paal, E. C. Neyts, C. C. W. Verlackt, and A. Bogaerts, "Effect of lipid peroxidation on membrane permeability of cancer and normal cells subjected to oxidative stress," Chemical Science, vol. 7, pp. 489-498, 2016.

[71] C. M. Wolff, J. F. Kolb, K. D. Weltmann, T. von Woedtke, and S. Bekeschus, "Combination treatment with cold physical plasma and pulsed electric fields augments ros production and cytotoxicity in lymphoma," Cancers (Basel), vol. 12, p. $845,2020$.

[72] L. Bundscherer, S. Nagel, S. Hasse et al., "Non-thermal plasma treatment induces mapk signaling in human monocytes," Open Chemistry, vol. 13, pp. 606-613, 2015.

[73] J. W. Chang, S. U. Kang, Y. S. Shin et al., "Non-thermal atmospheric pressure plasma inhibits thyroid papillary cancer cell invasion via cytoskeletal modulation, altered MMP-2/-9/uPA activity," PLoS One, vol. 9, article e92198, 2014.

[74] G. Pasqual-Melo, S. K. Sagwal, E. Freund et al., "Combination of gas plasma and radiotherapy has immunostimulatory potential and additive toxicity in murine melanoma cells in vitro," International Journal of Molecular Sciences, vol. 21, p. 1379, 2020.

[75] L. Lin, L. Wang, Y. Liu, C. Xu, Y. Tu, and J. Zhou, "Nonthermal plasma inhibits tumor growth and proliferation and enhances the sensitivity to radiation in vitro and in vivo," Oncology Reports, vol. 40, pp. 3405-3415, 2018.

[76] J. Lafontaine, J. S. Boisvert, A. Glory, S. Coulombe, and $\mathrm{P}$. Wong, "Synergy between non-thermal plasma with radiation therapy and olaparib in a panel of breast cancer cell lines," Cancers (Basel), vol. 12, 2020.

[77] C. M. Wolff, A. Steuer, I. Stoffels et al., "Combination of cold plasma and pulsed electric fields - a rationale for cancer patients in palliative care," Clinical Plasma Medicine, vol. 16, 2019.

[78] E. Griseti, J. Kolosnjaj-Tabi, L. Gibot et al., "Pulsed electric field treatment enhances the cytotoxicity of plasma- 
activated liquids in a three-dimensional human colorectal cancer cell model," Scientific Reports, vol. 9, p. 7583, 2019.

[79] R. Moniruzzaman, M. U. Rehman, Q. L. Zhao et al., "Cold atmospheric helium plasma causes synergistic enhancement in cell death with hyperthermia and an additive enhancement with radiation," Scientific Reports, vol. 7, p. 11659, 2017.

[80] M. Wang, B. M. Geilich, M. Keidar, and T. J. Webster, "Killing malignant melanoma cells with protoporphyrin ix-loaded polymersome-mediated photodynamic therapy and cold atmospheric plasma," International Journal of Nanomedicine, vol. 12, pp. 4117-4127, 2017.

[81] C. Y. Chen, Y. C. Cheng, and Y. J. Cheng, "Synergistic effects of plasma-activated medium and chemotherapeutic drugs in cancer treatment," Journal of Physics D: Applied Physics, vol. 51, 2018.

[82] G. Daeschlein, A. Hillmann, D. Gumbel et al., "Enhanced anticancer efficacy by drug chemotherapy and cold atmospheric plasma against melanoma and glioblastoma cell lines in vitro," IEEE Transactions on Radiation and Plasma Medical Sciences, vol. 2, pp. 153-159, 2018.

[83] K. R. Liedtke, E. Freund, M. Hermes et al., "Gas plasmaconditioned Ringer's lactate enhances the cytotoxic activity of cisplatin and gemcitabine in pancreatic cancer in vitro and in ovo," Cancers (Basel), vol. 12, p. 123, 2020.

[84] G. E. Conway, A. Casey, V. Milosavljevic et al., "Non-thermal atmospheric plasma induces ROS-independent cell death in U373MG glioma cells and augments the cytotoxicity of temozolomide," British Journal of Cancer, vol. 114, pp. 435-443, 2016.

[85] E. Gjika, S. Pal-Ghosh, M. E. Kirschner et al., "Combination therapy of cold atmospheric plasma (cap) with temozolomide in the treatment of U87MG glioblastoma cells," Scientific Reports, vol. 10, p. 16495, 2020.

[86] S. Mitra, P. Bhartiya, N. Kaushik et al., "Plasma-treated flammulina velutipes-derived extract showed anticancer potential in human breast cancer cells," Applied Sciences, vol. 10, p. 8395, 2020.

[87] P. Shaw, N. Kumar, D. Hammerschmid, A. Privat-Maldonado, S. Dewilde, and A. Bogaerts, "Synergistic effects of melittin and plasma treatment: a promising approach for cancer therapy," Cancers (Basel), vol. 11, 2019.

[88] A. Jalili, S. Irani, and R. Mirfakhraie, "Combination of cold atmospheric plasma and iron nanoparticles in breast cancer: gene expression and apoptosis study," Oncotargets and Therapy, vol. 9, pp. 5911-5917, 2016.

[89] M. Adhikari, B. Adhikari, B. Ghimire, S. Baboota, and E. H. Choi, "Cold atmospheric plasma and silymarin nanoemulsion activate autophagy in human melanoma cells," International Journal of Molecular Sciences, vol. 21, 2020.

[90] M. Adhikari, N. Kaushik, B. Ghimire et al., "Cold atmospheric plasma and silymarin nanoemulsion synergistically inhibits human melanoma tumorigenesis via targeting HGF/c-MET downstream pathway," Cell Communication and Signaling: CCS, vol. 17, p. 52, 2019.

[91] S. Aryal and G. Bisht, "New paradigm for a targeted cancer therapeutic approach: a short review on potential synergy of gold nanoparticles and cold atmospheric plasma," Biomedicine, vol. 5, 2017.

[92] X. Q. Cheng, W. Murphy, N. Recek et al., "Synergistic effect of gold nanoparticles and cold plasma on glioblastoma cancer therapy," Journal of Physics D: Applied Physics, vol. 47, article 335402, 2014.

[93] X. Q. Cheng, K. Rajjoub, J. Sherman et al., "Cold plasma accelerates the uptake of gold nanoparticles into glioblastoma cells," Plasma Processes and Polymers, vol. 12, pp. 1364-1369, 2015.

[94] B. B. Choi, M. S. Kim, U. K. Kim, J. W. Hong, H. J. Lee, and G. C. Kim, "Targeting neu protein in melanoma cells with non-thermal atmospheric pressure plasma and gold nanoparticles," Journal of Biomedical Nanotechnology, vol. 11, pp. 900-905, 2015.

[95] Z. He, K. Liu, E. Manaloto et al., "Cold atmospheric plasma induces ATP-dependent endocytosis of nanoparticles and synergistic U373MG cancer cell death," Scientific Reports, vol. 8, p. 5298, 2018.

[96] S. Irani, Z. Shahmirani, S. M. Atyabi, and S. Mirpoor, "Induction of growth arrest in colorectal cancer cells by cold plasma and gold nanoparticles," Archives of Medical Science, vol. 11, pp. 1286-1295, 2015.

[97] N. K. Kaushik, N. Kaushik, K. C. Yoo et al., "Low doses of PEG-coated gold nanoparticles sensitize solid tumors to cold plasma by blocking the PI3K/AKT-driven signaling axis to suppress cellular transformation by inhibiting growth and EMT," Biomaterials, vol. 87, pp. 118-130, 2016.

[98] G. Kim, S. R. Park, G. C. Kim, and J. K. Lee, “Targeted cancer treatment using anti-egfr and -tfr antibody-conjugated gold nanoparticles stimulated by nonthermal air plasma," Plasma Medicine, vol. 1, pp. 45-54, 2011.

[99] G. C. Kim, G. J. Kim, S. R. Park et al., “Air plasma coupled with antibody-conjugated nanoparticles: a new weapon against cancer," Journal of Physics D: Applied Physics, vol. 42, article 032005, 2009.

[100] W. Li, H. Yu, D. Ding et al., "Cold atmospheric plasma and iron oxide-based magnetic nanoparticles for synergetic lung cancer therapy," Free Radical Biology \& Medicine, vol. 130, pp. 71-81, 2019.

[101] R. Wahab, N. Kaushik, F. Khan et al., "Gold quantum dots impair the tumorigenic potential of glioma stem-like cells via beta-catenin downregulation in vitro," International Journal of Nanomedicine, vol. 14, pp. 1131-1148, 2019.

[102] H. Yu, Y. Wang, S. Wang et al., "Paclitaxel-loaded core-shell magnetic nanoparticles and cold atmospheric plasma inhibit non-small cell lung cancer growth," ACS Applied Materials \& Interfaces, vol. 10, pp. 43462-43471, 2018.

[103] W. Zhu, S. J. Lee, N. J. Castro, D. Yan, M. Keidar, and L. G. Zhang, "Synergistic effect of cold atmospheric plasma and drug loaded core-shell nanoparticles on inhibiting breast cancer cell growth," Scientific Reports, vol. 6, p. 21974, 2016.

[104] J. M. Pitt, A. Marabelle, A. Eggermont, J. C. Soria, G. Kroemer, and L. Zitvogel, "Targeting the tumor microenvironment: removing obstruction to anticancer immune responses and immunotherapy," Annals of Oncology, vol. 27, pp. 1482-1492, 2016.

[105] R. Brandenburg, "Dielectric barrier discharges: progress on plasma sources and on the understanding of regimes and single filaments," Plasma Sources Science and Technology, vol. 26, article 053001, 2017.

[106] J. Winter, R. Brandenburg, and K. D. Weltmann, "Atmospheric pressure plasma jets: an overview of devices and new directions," Plasma Sources Science and Technology, vol. 24, article 064001, 2015. 
[107] X. Lu, G. V. Naidis, M. Laroussi, S. Reuter, D. B. Graves, and K. Ostrikov, "Reactive species in non-equilibrium atmospheric-pressure plasmas: generation, transport, and biological effects," Physics Reports, vol. 630, pp. 1-84, 2016.

[108] J. Gay-Mimbrera, M. C. Garcia, B. Isla-Tejera, A. Rodero-Serrano, A. V. Garcia-Nieto, and J. Ruano, "Clinical and biological principles of cold atmospheric plasma application in skin cancer," Advances in Therapy, vol. 33, pp. 894-909, 2016.

[109] D. Yan, J. H. Sherman, and M. Keidar, "Cold atmospheric plasma, a novel promising anti-cancer treatment modality," Oncotarget, vol. 8, pp. 15977-15995, 2017.

[110] S. B. Karki, E. Yildirim-Ayan, K. M. Eisenmann, and H. Ayan, "Miniature dielectric barrier discharge nonthermal plasma induces apoptosis in lung cancer cells and inhibits cell migration," BioMed Research International, vol. 2017, Article ID 8058307, 12 pages, 2017.

[111] H. M. Joh, S. J. Kim, T. H. Chung, and S. H. Leem, "Comparison of the characteristics of atmospheric pressure plasma jets using different working gases and applications to plasmacancer cell interactions," AIP Advances, vol. 3, 2013.

[112] A. Schmidt-Bleker, R. Bansemer, S. Reuter, and K.D. Weltmann, "How to produce an nox- instead of oxbased chemistry with a cold atmospheric plasma jet," Plasma Processes and Polymers, vol. 13, pp. 1120-1127, 2016.

[113] S. Iseni, A. Schmidt-Bleker, J. Winter, K. D. Weltmann, and S. Reuter, "Atmospheric pressure streamer follows the turbulent argon air boundary in a $\mathrm{MHz}$ argon plasma jet investigated by OH-tracer PLIF spectroscopy," Journal of Physics D: Applied Physics, vol. 47, article 152001, 2014.

[114] S. Iseni, S. Zhang, A. F. H. van Gessel et al., "Nitric oxide density distributions in the effluent of an RF argon APPJ: effect of gas flow rate and substrate," New Journal of Physics, vol. 16, article 123011, 2014.

[115] P. Bourke, D. Ziuzina, L. Han, P. J. Cullen, and B. F. Gilmore, "Microbiological interactions with cold plasma," Journal of Applied Microbiology, vol. 123, pp. 308-324, 2017.

[116] S. Bekeschus, A. Schmidt, F. Niessner, T. Gerling, K. D. Weltmann, and K. Wende, "Basic research in plasma medicine - a throughput approach from liquids to cells," Journal of Visualized Experiments, no. 129, article e56331, 2017.

[117] S. Arndt, M. Landthaler, J. L. Zimmermann et al., "Effects of cold atmospheric plasma (CAP) on ss-defensins, inflammatory cytokines, and apoptosis-related molecules in keratinocytes in vitro and in vivo," PLoS One, vol. 10, article e0120041, 2015.

[118] M. Akhlaghi, H. Rajaei, A. S. Mashayekh et al., "Determination of the optimum conditions for lung cancer cells treatment using cold atmospheric plasma," Physics of Plasmas, vol. 23, 2016.

[119] E. Gjika, S. Pal-Ghosh, A. Tang et al., "Adaptation of operational parameters of cold atmospheric plasma for in vitro treatment of cancer cells," ACS Applied Materials \& Interfaces, vol. 10, pp. 9269-9279, 2018.

[120] H.-R. Metelmann, C. Seebauer, V. Miller et al., "Clinical experience with cold plasma in the treatment of locally advanced head and neck cancer," Clinical Plasma Medicine, vol. 9, pp. 6-13, 2018.

[121] M. Schuster, C. Seebauer, R. Rutkowski et al., "Visible tumor surface response to physical plasma and apoptotic cell kill in head and neck cancer," Journal of Cranio-Maxillo-Facial Surgery, vol. 44, pp. 1445-1452, 2016.
[122] A. Schmidt and S. Bekeschus, "Redox for repair: cold physical plasmas and Nrf2 signaling promoting wound healing," Antioxidants (Basel), vol. 7, p. 146, 2018.

[123] A. Schmidt-Bleker, J. Winter, A. Bosel, S. Reuter, and K. D. Weltmann, "On the plasma chemistry of a cold atmospheric argon plasma jet with shielding gas device," Plasma Sources Science and Technology, vol. 25, article 015005, 2016.

[124] A. Schmidt-Bleker, J. Winter, S. Iseni, M. Dunnbier, K. D. Weltmann, and S. Reuter, "Reactive species output of a plasma jet with a shielding gas device-combination of ftir absorption spectroscopy and gas phase modelling," Journal of Physics D: Applied Physics, vol. 47, article 145201, 2014.

[125] S. Reuter, T. von Woedtke, and K. D. Weltmann, "The kINPen-a review on physics and chemistry of the atmospheric pressure plasma jet and its applications," Journal of Physics D: Applied Physics, vol. 51, 2018.

[126] M. Dünnbier, M. M. Becker, S. Iseni et al., "Stability and excitation dynamics of an argon micro-scaled atmospheric pressure plasma jet," Plasma Sources Science and Technology, vol. 24, 2015.

[127] M. Dunnbier, A. Schmidt-Bleker, J. Winter et al., “Ambient air particle transport into the effluent of a cold atmospheric-pressure argon plasma jet investigated by molecular beam mass spectrometry," Journal of Physics D: Applied Physics, vol. 46, article 435203, 2013.

[128] K. Wende, P. Williams, J. Dalluge et al., "Identification of the biologically active liquid chemistry induced by a nonthermal atmospheric pressure plasma jet," Biointerphases, vol. 10, article 029518, 2015.

[129] H. Jablonowski, J. Santos Sousa, K. D. Weltmann, K. Wende, and S. Reuter, "Quantification of the ozone and singlet delta oxygen produced in gas and liquid phases by a non-thermal atmospheric plasma with relevance for medical treatment," Scientific Reports, vol. 8, p. 12195, 2018.

[130] P. J. Bruggeman, M. J. Kushner, B. R. Locke et al., "Plasmaliquid interactions: a review and roadmap," Plasma Sources Science and Technology, vol. 25, no. 5, article 053002, 2016.

[131] H. Jablonowski, A. Schmidt-Bleker, K. D. Weltmann, T. von Woedtke, and K. Wende, "Non-touching plasma-liquid interaction - where is aqueous nitric oxide generated?," Physical Chemistry Chemical Physics, vol. 20, pp. 25387-25398, 2018.

[132] C. E. Anderson, N. R. Cha, A. D. Lindsay, D. S. Clark, and D. B. Graves, "The role of interfacial reactions in determining plasma-liquid chemistry," Plasma Chemistry and Plasma Processing, vol. 36, pp. 1393-1415, 2016.

[133] H. Jablonowski and T. von Woedtke, "Research on plasma medicine-relevant plasma-liquid interaction: what happened in the past five years?," Clinical Plasma Medicine, vol. 3, pp. 42-52, 2015.

[134] E. M. Hanschmann, J. R. Godoy, C. Berndt, C. Hudemann, and C. H. Lillig, "Thioredoxins, glutaredoxins, and peroxiredoxins-molecular mechanisms and health significance: from cofactors to antioxidants to redox signaling," Antioxidants \& Redox Signaling, vol. 19, pp. 1539-1605, 2013.

[135] L. Galluzzi, I. Vitale, S. A. Aaronson et al., "Molecular mechanisms of cell death: recommendations of the nomenclature committee on cell death 2018," Cell Death and Differentiation, vol. 25, no. 3, pp. 486-541, 2018.

[136] G. Pistritto, D. Trisciuoglio, C. Ceci, A. Garufi, and G. D'Orazi, “Apoptosis as anticancer mechanism: function 
and dysfunction of its modulators and targeted therapeutic strategies," Aging (Albany NY), vol. 8, pp. 603-619, 2016.

[137] K. M. Debatin, "Apoptosis pathways in cancer and cancer therapy," Cancer Immunology, Immunotherapy, vol. 53, pp. 153-159, 2004.

[138] G. Bauer, D. Sersenova, D. B. Graves, and Z. Machala, "Cold atmospheric plasma and plasma-activated medium trigger rons-based tumor cell apoptosis," Scientific Reports, vol. 9, p. 14210, 2019.

[139] Y. J. Guo, W. W. Pan, S. B. Liu, Z. F. Shen, Y. Xu, and L. L. $\mathrm{Hu}$, "ERK/MAPK signalling pathway and tumorigenesis," Experimental and Therapeutic Medicine, vol. 19, pp. 19972007, 2020.

[140] M. Ishaq, M. M. Evans, and K. K. Ostrikov, "Effect of atmospheric gas plasmas on cancer cell signaling," International Journal of Cancer, vol. 134, pp. 1517-1528, 2014.

[141] P. Bragado, A. Armesilla, A. Silva, and A. Porras, "Apoptosis by cisplatin requires p53 mediated p38alpha MAPK activation through ROS generation," Apoptosis, vol. 12, pp. 17331742, 2007.

[142] N. Kaushik, N. Uddin, G. B. Sim et al., "Responses of solid tumor cells in dmem to reactive oxygen species generated by non-thermal plasma and chemically induced ROS systems," Scientific Reports, vol. 5, p. 8587, 2015.

[143] M. Osaki, M. Oshimura, and H. Ito, "PI3K-Akt pathway: its functions and alterations in human cancer," Apoptosis, vol. 9, pp. 667-676, 2004.

[144] J. Xia, W. Zeng, Y. Xia et al., "Cold atmospheric plasma induces apoptosis of melanoma cells via sestrin2-mediated nitric oxide synthase signaling," Journal of Biophotonics, vol. 12, article e201800046, 2019.

[145] S. A. E. Ibrahim, A. Abudu, E. Johnson, N. Aftab, S. Conrad, and M. Fluck, "The role of AP-1 in self-sufficient proliferation and migration of cancer cells and its potential impact on an autocrine/paracrine loop," Oncotarget, vol. 9, pp. 34259-34278, 2018.

[146] A. Schmidt, K. Rodder, S. Hasse et al., "Redox-regulation of activator protein 1 family members in blood cancer cell lines exposed to cold physical plasma-treated medium," Plasma Processes and Polymers, vol. 13, pp. 1179-1188, 2016.

[147] J. F. Liu, W. W. Deng, L. Chen et al., "Inhibition of JAK2/ STAT3 reduces tumor-induced angiogenesis and myeloidderived suppressor cells in head and neck cancer," Molecular Carcinogenesis, vol. 57, pp. 429-439, 2018.

[148] J. Tornin, M. Mateu-Sanz, A. Rodriguez, C. Labay, R. Rodriguez, and C. Canal, "Pyruvate plays a main role in the antitumoral selectivity of cold atmospheric plasma in osteosarcoma," Scientific Reports, vol. 9, p. 10681, 2019.

[149] C. W. Yun and S. H. Lee, "The roles of autophagy in cancer," International Journal of Molecular Sciences, vol. 19, 2018.

[150] Z. Hamurcu, N. Delibasi, S. Gecene et al., "Targeting LC3 and beclin-1 autophagy genes suppresses proliferation, survival, migration and invasion by inhibition of cyclin-D1 and uPAR/integrin beta1/Src signaling in triple negative breast cancer cells," Journal of Cancer Research and Clinical Oncology, vol. 144, pp. 415-430, 2018.

[151] M. Alimohammadi, M. Golpur, F. Sohbatzadeh et al., "Cold atmospheric plasma is a potent tool to improve chemotherapy in melanoma in vitro and in vivo," Biomolecules, vol. 10, 2020.
[152] L. Shi, F. Ito, Y. Wang et al., "Non-thermal plasma induces a stress response in mesothelioma cells resulting in increased endocytosis, lysosome biogenesis and autophagy," Free Radical Biology \& Medicine, vol. 108, pp. 904-917, 2017.

[153] N. Yoshikawa, W. Liu, K. Nakamura et al., "Plasma-activated medium promotes autophagic cell death along with alteration of the mTOR pathway," Scientific Reports, vol. 10, p. 1614, 2020.

[154] X. Zhen, H. N. Sun, R. Liu, H. S. Choi, and D. S. Lee, "Nonthermal plasma-activated medium induces apoptosis of Aspc1 cells through the ROS-dependent autophagy pathway," In Vivo, vol. 34, pp. 143-153, 2020.

[155] Y. Fang, S. Tian, Y. Pan et al., "Pyroptosis: a new frontier in cancer," Biomedicine \& Pharmacotherapy, vol. 121, article 109595, 2020.

[156] X. Xia, X. Wang, Z. Cheng et al., "The role of pyroptosis in cancer: pro-cancer or pro-"host"?," Cell Death \& Disease, vol. 10, p. 650, 2019.

[157] X. Yang, G. Chen, K. N. Yu et al., "Cold atmospheric plasma induces GSDME-dependent pyroptotic signaling pathway via ROS generation in tumor cells," Cell Death \& Disease, vol. 11, p. 295, 2020.

[158] J. Y. Cao and S. J. Dixon, "Mechanisms of ferroptosis," Cellular and Molecular Life Sciences, vol. 73, pp. 2195-2209, 2016.

[159] Y. Xie, W. Hou, X. Song et al., "Ferroptosis: process and function," Cell Death and Differentiation, vol. 23, pp. 369-379, 2016.

[160] Y. Mou, J. Wang, J. Wu et al., "Ferroptosis, a new form of cell death: opportunities and challenges in cancer," Journal of Hematology \& Oncology, vol. 12, p. 34, 2019.

[161] B. Hassannia, P. Vandenabeele, and T. Vanden Berghe, "Targeting ferroptosis to iron out cancer," Cancer Cell, vol. 35, pp. 830-849, 2019.

[162] L. Jiang, N. Kon, T. Li et al., "Ferroptosis as a p53-mediated activity during tumour suppression," Nature, vol. 520, pp. 57-62, 2015.

[163] S. Bekeschus, S. Eisenmann, S. K. Sagwal et al., "Xct (slc7a11) expression confers intrinsic resistance to physical plasma treatment in tumor cells," Redox Biology, vol. 30, article 101423, 2020.

[164] T. Furuta, L. Shi, and S. Toyokuni, "Non-thermal plasma as a simple ferroptosis inducer in cancer cells: a possible role of ferritin," Pathology International, vol. 68, pp. 442-443, 2018.

[165] K. Sato, L. Shi, F. Ito et al., "Non-thermal plasma specifically kills oral squamous cell carcinoma cells in a catalytic Fe(ii)dependent manner," Journal of Clinical Biochemistry and Nutrition, vol. 65, pp. 8-15, 2019.

[166] A. Lin, B. Truong, S. Patel et al., "Nanosecond-pulsed DBD plasma-generated reactive oxygen species trigger immunogenic cell death in A549 lung carcinoma cells through intracellular oxidative stress," International Journal of Molecular Sciences, vol. 18, p. 966, 2017.

[167] Y. Liu and G. Zeng, "Cancer and innate immune system interactions: translational potentials for cancer immunotherapy," Journal of Immunotherapy, vol. 35, pp. 299-308, 2012.

[168] A. Marcus, B. G. Gowen, T. W. Thompson et al., "Recognition of tumors by the innate immune system and natural killer cells," Advances in Immunology, vol. 122, pp. 91-128, 2014.

[169] D. V. Krysko, A. D. Garg, A. Kaczmarek, O. Krysko, P. Agostinis, and P. Vandenabeele, "Immunogenic cell death 
and damps in cancer therapy," Nature Reviews. Cancer, vol. 12, pp. 860-875, 2012.

[170] J. Zhou, G. Wang, Y. Chen, H. Wang, Y. Hua, and Z. Cai, "Immunogenic cell death in cancer therapy: present and emerging inducers," Journal of Cellular and Molecular Medicine, vol. 23, pp. 4854-4865, 2019.

[171] S. Bekeschus, A. Mueller, V. Miller, U. Gaipl, and K.D. Weltmann, "Physical plasma elicits immunogenic cancer cell death and mitochondrial singlet oxygen," IEEE Transactions on Radiation and Plasma Medical Sciences, vol. 2, pp. 138-146, 2018.

[172] S. Bekeschus, K. Rödder, B. Fregin et al., "Toxicity and immunogenicity in murine melanoma following exposure to physical plasma-derived oxidants," Oxidative Medicine and Cellular Longevity, vol. 2017, Article ID 4396467, 12 pages, 2017.

[173] K. Rödder, J. Moritz, V. Miller et al., “Activation of murine immune cells upon co-culture with plasma-treated B16F10 melanoma cells," Applied Sciences, vol. 9, p. 660, 2019.

[174] A. G. Lin, B. Xiang, D. J. Merlino et al., "Non-thermal plasma induces immunogenic cell death in vivo in murine CT26 colorectal tumors," Oncoimmunology, vol. 7, article e1484978, 2018.

[175] K. R. Liedtke, E. Freund, C. Hackbarth, C.-D. Heidecke, L.I. Partecke, and S. Bekeschus, "A myeloid and lymphoid infiltrate in murine pancreatic tumors exposed to plasma-treated medium," Clinical Plasma Medicine, vol. 11, pp. 10-17, 2018.

[176] J. Cook and T. Hagemann, "Tumour-associated macrophages and cancer," Current Opinion in Pharmacology, vol. 13, pp. 595-601, 2013.

[177] T. F. Gajewski, H. Schreiber, and Y. X. Fu, "Innate and adaptive immune cells in the tumor microenvironment," Nature Immunology, vol. 14, pp. 1014-1022, 2013.

[178] N. K. Kaushik, N. Kaushik, M. Adhikari et al., "Preventing the solid cancer progression via release of anticancer-cytokines in co-culture with cold plasma-stimulated macrophages," Cancers (Basel), vol. 11, 2019.

[179] L. Crestale, R. Laurita, A. Liguori et al., "Cold atmospheric pressure plasma treatment modulates human monocytes/ macrophages responsiveness," Plasma, vol. 1, pp. 261-276, 2018.

[180] S. Bekeschus, J. Kolata, A. Muller et al., "Differential viability of eight human blood mononuclear cell subpopulations after plasma treatment," Plasma Medicine, vol. 3, pp. 1-13, 2013.

[181] A. Lin, B. Truong, G. Fridman, A. A. Fridman, and V. Miller, "Immune cells enhance selectivity of nanosecond-pulsed dbd plasma against tumor cells," Plasma Medicine, vol. 7, 2017.

[182] A. Lin, B. Truong, A. Pappas et al., "Uniform nanosecond pulsed dielectric barrier discharge plasma enhances antitumor effects by induction of immunogenic cell death in tumors and stimulation of macrophages," Plasma Processes and Polymers, vol. 12, pp. 1392-1399, 2015.

[183] N. K. Kaushik, N. Kaushik, B. Min et al., "Cytotoxic macrophage-released tumour necrosis factor-alpha (TNFalpha) as a killing mechanism for cancer cell death after cold plasma activation," Journal of Physics D: Applied Physics, vol. 49, article 084001, 2016.

[184] J. Jackute, M. Zemaitis, D. Pranys et al., "Distribution of M1 and M2 macrophages in tumor islets and stroma in relation to prognosis of non-small cell lung cancer," BMC Immunology, vol. 19, p. 3, 2018.
[185] B. W. Tse, K. F. Scott, and P. J. Russell, "Paradoxical roles of tumour necrosis factor-alpha in prostate cancer biology," Prostate Cancer, vol. 2012, Article ID 128965, 8 pages, 2012.

[186] E. Freund, J. Moritz, M. Stope, C. Seebauer, A. Schmidt, and S. Bekeschus, "Plasma-derived reactive species shape a differentiation profile in human monocytes," Applied Sciences, vol. 9, 2019.

[187] S. Bekeschus, V. Ressel, E. Freund, N. Gelbrich, A. Mustea, and M. B. Stope, "Gas plasma-treated prostate cancer cells augment myeloid cell activity and cytotoxicity," Antioxidants (Basel), vol. 9, p. 323, 2020.

[188] S. Y. Gun, S. W. L. Lee, J. L. Sieow, and S. C. Wong, “Targeting immune cells for cancer therapy," Redox Biology, vol. 25, article 101174, 2019.

[189] C. Fu and A. Jiang, "Dendritic cells and cd8 t cell immunity in tumor microenvironment," Frontiers in Immunology, vol. 9, p. 3059, 2018.

[190] S. Bekeschus, R. Clemen, and H.-R. Metelmann, "Potentiating anti-tumor immunity with physical plasma," Clinical Plasma Medicine, vol. 12, pp. 17-22, 2018.

[191] M. Khalili, L. Daniels, A. Lin et al., "Non-thermal plasmainduced immunogenic cell death in cancer: a topical review," Journal of Physics D: Applied Physics, vol. 52, 2019.

[192] G. Chen, Z. Chen, D. Wen et al., "Transdermal cold atmospheric plasma-mediated immune checkpoint blockade therapy," Proceedings of the National Academy of Sciences of the United States of America, vol. 117, no. 7, pp. 3687-3692, 2020.

[193] A. Lin, Y. Gorbanev, J. De Backer et al., "Non-thermal plasma as a unique delivery system of short-lived reactive oxygen and nitrogen species for immunogenic cell death in melanoma cells," Advanced Science, vol. 6, p. 1802062, 2019.

[194] J. van Loenhout, T. Flieswasser, L. Freire Boullosa et al., "Cold atmospheric plasma-treated pbs eliminates immunosuppressive pancreatic stellate cells and induces immunogenic cell death of pancreatic cancer cells," Cancers (Basel), vol. 11, no. 10, 2019.

[195] S. Bekeschus, R. Clemen, F. Niessner, S. K. Sagwal, E. Freund, and A. Schmidt, "Medical gas plasma jet technology targets murine melanoma in an immunogenic fashion," Advanced Science, vol. 7, p. 1903438, 2020.

[196] K. Mizuno, Y. Shirakawa, T. Sakamoto, H. Ishizaki, Y. Nishijima, and R. Ono, "Plasma-induced suppression of recurrent and reinoculated melanoma tumors in mice," IEEE Transactions on Radiation and Plasma Medical Sciences, vol. 2, pp. 353-359, 2018.

[197] K. Mizuno, K. Yonetamari, Y. Shirakawa, T. Akiyama, and R. Ono, "Anti-tumor immune response induced by nanosecond pulsed streamer discharge in mice," Journal of Physics D: Applied Physics, vol. 50, p. 12LT01, 2017.

[198] R. Clemen, E. Freund, D. Mrochen et al., "Gas plasma technology augments ovalbumin immunogenicity and OT-II T cell activation conferring tumor protection in mice," Advanced Science, vol. 8, p. 2003395, 2021.

[199] R. Clemen and S. Bekeschus, "ROS cocktails as an adjuvant for personalized antitumor vaccination?," Vaccine, vol. 9, 2021.

[200] H. R. Metelmann, C. Seebauer, R. Rutkowski, M. Schuster, S. Bekeschus, and P. Metelmann, "Treating cancer with cold physical plasma: on the way to evidence-based medicine," Contributions to Plasma Physics, vol. 58, pp. 415-419, 2018.

[201] S. Hartwig, S. Preissner, J. O. Voss et al., "The feasibility of cold atmospheric plasma in the treatment of complicated 
wounds in cranio-maxillo-facial surgery," Journal of CranioMaxillo-Facial Surgery, vol. 45, pp. 1724-1730, 2017.

[202] S. Hartwig, C. Doll, J. O. Voss, M. Hertel, S. Preissner, and J. D. Raguse, "Treatment of wound healing disorders of radial forearm free flap donor sites using cold atmospheric plasma: a proof of concept," Journal of Oral and Maxillofacial Surgery, vol. 75, pp. 429-435, 2017.

[203] P. C. Friedman, V. Miller, G. Fridman, A. Lin, and A. Fridman, "Successful treatment of actinic keratoses using nonthermal atmospheric pressure plasma: a case series," Journal of the American Academy of Dermatology, vol. 76, pp. 349-350, 2017.

[204] M. Wirtz, I. Stoffels, J. Dissemond, D. Schadendorf, and A. Roesch, "Actinic keratoses treated with cold atmospheric plasma," Journal of the European Academy of Dermatology and Venereology, vol. 32, pp. e37-e39, 2018.

[205] P. C. Friedman, V. Miller, G. Fridman, and A. Fridman, "Use of cold atmospheric pressure plasma to treat warts: a potential therapeutic option," Clinical and Experimental Dermatology, vol. 44, pp. 459-461, 2019.

[206] P. C. Friedman, G. Fridman, and A. Fridman, "Using cold plasma to treat warts in children: a case series," Pediatric Dermatology, vol. 37, pp. 706-709, 2020.

[207] S. Bekeschus, J. Moritz, I. Helfrich et al., "Ex vivo exposure of human melanoma tissue to cold physical plasma elicits apoptosis and modulates inflammation," Applied Sciences, vol. 10, 2020.

[208] M. Linneweh, "Physical cold atmospheric plasma for the treatment of cervical intraepithelial neoplasia (capcin)," 2017, https://clinicaltrials.gov/ct2/show/NCT03218436.

[209] J. Canady, "Canady helios cold plasma scalpel treatment at the surgical margin and macroscopic tumor sites," 2019, https://clinicaltrials.gov/ct2/show/NCT04267575.

[210] P. C. Friedman, "Using a cold atmospheric plasma device to treat skin disorders," 2016, https://clinicaltrials.gov/ct2/ show/NCT02759900.

[211] P. C. Friedman, "Cold plasma to treat hair loss," 2020, https:// clinicaltrials.gov/ct2/show/NCT04379752.

[212] S. Bekeschus, J. Kolata, C. Winterbourn et al., "Hydrogen peroxide: a central player in physical plasma-induced oxidative stress in human blood cells," Free Radical Research, vol. 48, pp. 542-549, 2014.

[213] B. Stratmann, T. C. Costea, C. Nolte et al., "Effect of cold atmospheric plasma therapy vs standard therapy placebo on wound healing in patients with diabetic foot ulcers: a randomized clinical trial," JAMA Network Open, vol. 3, article e2010411, 2020.

[214] A. Schmidt, T. von Woedtke, B. Vollmar, S. Hasse, and S. Bekeschus, "Nrf2 signaling and inflammation are key events in physical plasma-spurred wound healing," Theranostics, vol. 9, pp. 1066-1084, 2019.

[215] S. Bekeschus, A. Schmidt, K.-D. Weltmann, and T. von Woedtke, "The plasma jet kINPen - a powerful tool for wound healing," Clinical Plasma Medicine, vol. 4, pp. 1928, 2016.

[216] K. Wende, S. Bekeschus, A. Schmidt et al., "Risk assessment of a cold argon plasma jet in respect to its mutagenicity," Mutation Research, Genetic Toxicology and Environmental Mutagenesis, vol. 798-799, pp. 48-54, 2016.

[217] S. Bekeschus, A. Schmidt, A. Kramer et al., "High throughput image cytometry micronucleus assay to investigate the pres- ence or absence of mutagenic effects of cold physical plasma," Environmental and Molecular Mutagenesis, vol. 59, pp. 268277, 2018.

[218] S. Bekeschus, C. S. Schütz, F. Nießner et al., "Elevated H2AX phosphorylation observed with kINPen plasma treatment is not caused by ROS-mediated DNA damage but is the consequence of apoptosis," Oxidative Medicine and Cellular Longevity, vol. 2019, Article ID 8535163, 15 pages, 2019.

[219] S. Kluge, S. Bekeschus, C. Bender et al., "Investigating the mutagenicity of a cold argon-plasma jet in an HET-MM model," PLoS One, vol. 11, article e0160667, 2016.

[220] A. Schmidt, T. V. Woedtke, J. Stenzel et al., "One year followup risk assessment in SKH-1 mice and wounds treated with an argon plasma jet," International Journal of Molecular Sciences, vol. 18, 2017.

[221] L. Jablonowski, T. Kocher, A. Schindler et al., "Side effects by oral application of atmospheric pressure plasma on the mucosa in mice," PLoS One, vol. 14, article e0215099, 2019.

[222] R. Rutkowski, G. Daeschlein, T. von Woedtke, R. Smeets, M. Gosau, and H. R. Metelmann, "Long-term risk assessment for medical application of cold atmospheric pressure plasma," Diagnostics (Basel), vol. 10, 2020.

[223] M. Schuster, R. Rutkowski, A. Hauschild et al., "Side effects in cold plasma treatment of advanced oral cancer-clinical data and biological interpretation," Clinical Plasma Medicine, vol. 10, pp. 9-15, 2018.

[224] H.-R. Metelmann, T. Von Woedtke, and K.-D. Weltmann, Comprehensive Clinical Plasma Medicine: Cold Physical Plasma for Medical Application, Springer, 2018.

[225] J. Heinlin, G. Isbary, W. Stolz et al., "A randomized two-sided placebo-controlled study on the efficacy and safety of atmospheric non-thermal argon plasma for pruritus," Journal of the European Academy of Dermatology and Venereology, vol. 27, pp. 324-331, 2013.

[226] G. Isbary, J. L. Zimmermann, T. Shimizu et al., "Non-thermal plasma-more than five years of clinical experience," Clinical Plasma Medicine, vol. 1, pp. 19-23, 2013.

[227] V. Boxhammer, Y. F. Li, J. Koritzer et al., "Investigation of the mutagenic potential of cold atmospheric plasma at bactericidal dosages," Mutation Research, vol. 753, pp. 23-28, 2013.

[228] O. Assadian, K. J. Ousey, G. Daeschlein et al., "Effects and safety of atmospheric low-temperature plasma on bacterial reduction in chronic wounds and wound size reduction: a systematic review and meta-analysis," International Wound Journal, vol. 16, pp. 103-111, 2019.

[229] E. Timmermann, R. Bansemer, T. Gerling et al., "Piezoelectric-driven plasma pen with multiple nozzles used as a medical device: risk estimation and antimicrobial efficacy," Journal of Physics D: Applied Physics, vol. 54, 2021.

[230] L. Miebach, E. Freund, S. Horn et al., "Tumor cytotoxicity and immunogenicity of a novel $\mathrm{v}$-jet neon plasma source compared to the kINPen," Scientific Reports, vol. 11, p. 136, 2021.

[231] A. Lehmann, F. Pietag, and T. Arnold, "Human health risk evaluation of a microwave-driven atmospheric plasma jet as medical device," Clinical Plasma Medicine, vol. 7-8, pp. 1623, 2017.

[232] S. Kos, T. Blagus, M. Cemazar, G. Filipic, G. Sersa, and U. Cvelbar, "Safety aspects of atmospheric pressure helium plasma jet operation on skin: in vivo study on mouse skin," PLoS One, vol. 12, article e0174966, 2017. 
[233] F. Nejat, N.-S. Nabavi, M.-A. Nejat, H. Aghamollaei, and K. Jadidi, "Safety evaluation of the plasma on ocular surface tissue: an animal study and histopathological findings," Clinical Plasma Medicine, vol. 14, 2019.

[234] D. Xu, Q. Cui, Y. Xu et al., "Systemic study on the safety of immuno-deficient nude mice treated by atmospheric plasma-activated water," Plasma Science and Technology, vol. 20, 2018.

[235] M. S. Mann, R. Tiede, K. Gavenis et al., "Introduction to dinspecification 91315 based on the characterization of the plasma jet kINPen ${ }^{\circledR}$ med," Clinical Plasma Medicine, vol. 4, pp. 35-45, 2016.

[236] F. Utsumi, H. Kajiyama, K. Nakamura et al., "Effect of indirect nonequilibrium atmospheric pressure plasma on antiproliferative activity against chronic chemo-resistant ovarian cancer cells in vitro and in vivo," PLoS One, vol. 8, article e81576, 2013.

[237] A. Schmidt, S. Bekeschus, T. von Woedtke, and S. Hasse, "Cell migration and adhesion of a human melanoma cell line is decreased by cold plasma treatment," Clinical Plasma Medicine, vol. 3, pp. 24-31, 2015.

[238] D. Xu, X. Luo, Y. Xu et al., "The effects of cold atmospheric plasma on cell adhesion, differentiation, migration, apoptosis and drug sensitivity of multiple myeloma," Biochemical and Biophysical Research Communications, vol. 473, pp. 11251132, 2016.

[239] J. I. Ikeda, H. Tanaka, K. Ishikawa, H. Sakakita, Y. Ikehara, and M. Hori, "Plasma-activated medium (PAM) kills human cancer-initiating cells," Pathology International, vol. 68, pp. 23-30, 2018.

[240] K. Nakamura, Y. Peng, F. Utsumi et al., "Novel intraperitoneal treatment with non-thermal plasma-activated medium inhibits metastatic potential of ovarian cancer cells," Scientific Reports, vol. 7, p. 6085, 2017.

[241] M. Akter, A. Jangra, S. A. Choi, E. H. Choi, and I. Han, "Nonthermal atmospheric pressure bio-compatible plasma stimulates apoptosis via p38/MAPK mechanism in U87 malignant glioblastoma," Cancers (Basel), vol. 12, 2020.

[242] G. Daeschlein, M. Napp, S. Lutze et al., "Skin and wound decontamination of multidrug-resistant bacteria by cold atmospheric plasma coagulation," Journal der Deutschen Dermatologischen Gesellschaft, vol. 13, pp. 143-150, 2015.

[243] L. Hilker, T. von Woedtke, K. D. Weltmann, and H. G. Wollert, "Cold atmospheric plasma: a new tool for the treatment of superficial driveline infections," European Journal of Cardio-Thoracic Surgery, vol. 51, pp. 186-187, 2017.

[244] H. H. Reitberger, M. Czugala, C. Chow et al., "Argon cold plasma-a novel tool to treat therapy-resistant corneal infections," American Journal of Ophthalmology, vol. 190, pp. 150-163, 2018.

[245] F. Brehmer, H. A. Haenssle, G. Daeschlein et al., "Alleviation of chronic venous leg ulcers with a hand-held dielectric barrier discharge plasma generator (PlasmaDerm $\left({ }^{\circledR}\right)$ VU-2010): results of a monocentric, two-armed, open, prospective, randomized and controlled trial (NCT01415622)," Journal of the European Academy of Dermatology and Venereology, vol. 29, pp. 148-155, 2015.

[246] J. D. Holcomb, M. Kelly, T. K. Hamilton, and J. B. DeLozier 3rd., "A prospective study evaluating the use of helium plasma for dermal resurfacing," Lasers in Surgery and Medicine, 2020.
[247] E. Middelkoop, "Cold plasma for wound treatment, safety study," 2017, https://clinicaltrials.gov/ct2/show/ NCT03007264.

[248] J. N. Roe, "Early feasibility study to evaluate the efficacy and safety of the renewalnail ${ }^{\mathrm{TM}}$ plasma treatment system in patients with mild to moderate onychomycosis (fungal nail)," 2017, https://clinicaltrials.gov/ct2/show/NCT03072550.

[249] N. V. Tuktagulov, "Cold argon plasma (CAP) application in the wound treatment after open hemorrhoidectomy," 2019, https://clinicaltrials.gov/ct2/show/NCT03907306. 